\title{
Regulation of Human Cytochrome P4501A1 (hCYP1A1): A Plausible Target for Chemoprevention?
}

\author{
Rebeca Santes-Palacios, Diego Ornelas-Ayala, Noel Cabañas, \\ Ana Marroquín-Pérez, Alexis Hernández-Magaña, Sitlali del Rosario Olguín-Reyes, \\ Rafael Camacho-Carranza, and Jesús Javier Espinosa-Aguirre
}

Departamento de Medicina Genómica y Toxicología Ambiental, Instituto de Investigaciones Biomédicas, UNAM,

Correspondence should be addressed to Jesús Javier Espinosa-Aguirre; jjea99@gmail.com

Received 5 September 2016; Revised 9 November 2016; Accepted 13 November 2016

Academic Editor: Young-Mi Lee

Copyright (C) 2016 Rebeca Santes-Palacios et al. This is an open access article distributed under the Creative Commons Attribution License, which permits unrestricted use, distribution, and reproduction in any medium, provided the original work is properly cited.

Human cytochrome P450 1A1 (hCYP1A1) has been an object of study due to its role in precarcinogen metabolism; for this reason it is relevant to know more in depth the mechanisms that rule out its expression and activity, which make this enzyme a target for the development of novel chemiopreventive agents. The aim of this work is to review the origin, regulation, and structural and functional characteristics of CYP1A1 letting us understand its role in the bioactivation of precarcinogen and the consequences of its modulation in other physiological processes, as well as guide us in the study of this important protein.

\section{Introduction}

Cytochrome P450 (CYP) is a superfamily of hemoproteins, with monooxygenase activity, which are spread into the three domains of life. They are biological catalysts that metabolize endogenous compounds such as hormones, bile acids, cholesterol, and xenobiotics like environmental pollutants and drugs. The hCYP1Al is an enzyme of biomedical and toxicological interest, which catalyzes the biotransformation of polycyclic aryl hydrocarbons (PAHs), aromatic amines, and polychlorinated biphenyls into polar compounds, which can be conjugated to soluble compounds suitable for excretion by urine or bile. Nevertheless, under specific circumstances, this enzyme catalyzes the bioactivation of compounds capable of reacting with macromolecules, such as DNA, leading to the start of mutagenic process.

Every day, we are exposed to compounds that are substrates of CYP1A1, through environmental pollution, food, and, particularly, cigarette smoke. The importance of this protein in chemical carcinogenesis induced by PAHs has been demonstrated in CYP1 knockout mice, in which the lack of this protein shows less formation of adducts PAH-DNA
$[1,2]$. In addition, rodent exposition to CYP1Al inhibitors diminished the number of tumors induced by PAHs $[3,4]$.

Epidemiologic studies focused on the relationship among PAH exposition, PAH-DNA adducts level, and cancer incidence in humans demonstrate an increased risk in colon adenocarcinoma [5], breast cancer [6], and lung cancer [7] in those individuals with higher levels of adducts.

This data suggests that imbalance between detoxification and bioactivation of carcinogens, independence of enzyme catalysis, regulation of gene expression of CYP1A1, and cellular environment are crucial factors at the beginning of chemical carcinogenesis process. Because of this, several questions are still to answer; we propose that a global view of the function and regulation of this enzyme would help to answer these questions; thus, the aim of this work is to integrate the knowledge that has been generated until now about the origin, regulation, and structural characteristics of hCYP1Al.

\section{Some Aspects of CYP1A1 Evolution}

CYPs constitute a superfamily of ancient genes encoding to heme-thiolate proteins that catalyze the monooxygenation of 
endogenous and exogenous substrates in bacteria, archaea, eukaryotes, and viruses $[8,9]$; therefore these proteins must descend from a prokaryotic common ancestor $\sim 3$ billion years ago, before the oxygenation of the atmosphere and emergence of eukaryotic cells $[10,11]$.

The first CYP proteins were involved in the biosynthesis of compounds required for the formation and maintenance of cell structures and then following CYP proteins coevolved as defense mechanisms in plants and insects and more recently a set of these enzymes evolved in response to xenobiotics [12, 13].

CYPs belonging to families 1-4 are the main mediators of exogenous metabolism; however, cytochromes from family 1 are of particular biomedical and toxicological interest because of their affinity to halogenated polycyclic, aromatic amines, aromatic hydrocarbons, and endogenous compounds, whose metabolites can be toxic, mutagenic, or carcinogenic [14-16].

CYP genes of family 1 are grouped into six subfamilies: CYP1A, CYP1B, CYP1C, CYP1D, CYP1E, and CYP1F, from these $1 \mathrm{E}$ and $1 \mathrm{~F}$ are found in urochordates; $1 \mathrm{~A}, 1 \mathrm{~B}, 1 \mathrm{C}$, and $1 \mathrm{D}$ are found in fish and amphibians; in mammals the subfamilies that are mainly distributed are $1 \mathrm{~A}$ and $1 \mathrm{~B}$ and in some cases 1D [9, 17].

CYP1A and CYP1B diverged from a common ancestor $\sim 450$ million years ago (Ma); thus, CYP1A appears early in aquatic vertebrates, as a single copy, which has been identified in teleost fish, while mammals and birds have paralogous genes of CYP1A: CYP1A1, CYP1A2, in mammals, and CYP1A4, CYP1A5 in birds, which emerged $\sim 250 \mathrm{Ma}$ from a duplication event and one inversion, common for both lineages [15, 18, 19] (Figure 1).

In humans, the CYP1A1 gene consists of $6069 \mathrm{bp}$ and is located at the CYP1A1_CYP1A2 locus on chromosome $15 q 24.1$, sharing a regulatory region of 23306 bp with the CYP1A2 gene that is oriented in opposite direction. The 5 ' flanking region is shared by both genes and contains a bidirectional promoter and DNA motifs, known as response elements, that activate and regulate the expression of these genes $[20,21]$.

The participation of multiple signaling pathways in the regulation of the hCYP1A1 transcription has been reported. Next, an overview about the pathways involved in this regulation is reviewed.

\section{Upregulation of CYP1A1}

The constitutive $h C Y P 1 A 1$ gene has low level of expression in extrahepatic tissues of adult humans. However, liver and extrahepatic expression of this enzyme can be induced by many substrates through multiple pathways. The aryl hydrocarbon receptor (AHR) pathway has been widely studied and it appears to be the main protein receptor that influences CYP1A1 induction. The AHR is a cytosolic ligand-activated transcription factor associated with two heat shock proteins of $90 \mathrm{kDa}$ (Hsp90), a hepatitis B virus X-associated protein (XAP2), and a chaperone of $23 \mathrm{kDa}(\mathrm{p} 23)$. This receptor is activated by endogenous ligands and several xenobiotics such as polycyclic aromatic hydrocarbons (PAHs), heterocyclic amines, and halogenated biphenyls [22]. After ligand activation, AHR undergoes conformational changes that promote its translocation into the nucleus, via $\beta$ importin, where it is dissociated from the chaperone proteins (Hsp90, XAP2, and p23), and binds to the nuclear translocator AHR (ARNT) [23, 24]; then the formed AHR-ARNT complex (AHRC) binds to xenobiotic responsive elements (XRE) ( $5^{\prime}$-TNGCGTG-3') located at the enhancer element [25].

Thirteen XRE have been identified in the regulatory region of human CYP1A1 [25]. It has been speculated that they are located at the major grooves of the DNA and they would be exposed during nucleosomal movements, allowing the AHRC binding. In turn, this promotes the recruitment of chromatin remodeling proteins such as p300, SRC1/2, and BRG1 [26], subsequent hyperacetylation of lysines 9 and 14 in histone 3 (H3K9ac and $\mathrm{H} 3 \mathrm{~K} 14 \mathrm{ac}$ ), and methylation of lysine 4 in histone 3 (H3K4me) (from dimethylation to trimethylation) at the promoter; meanwhile hyperacetylation of lysine 16 in histone 4 ( $\mathrm{AcH} 4 \mathrm{~K} 16)$ and increased phosphorylation of serine 10 in histone 3 ( $\mathrm{pH} 3 \mathrm{~S} 10)$ take place at the enhancer element. The increase of acetylation marks at the promoter region of mouse CYP1A1 (mCYP1A1) is consistent with the releasing of a basal repressive complex, which is composed of histone deacetylase 1 (HDAC1) and DNA methyltransferase 1 (DNMT1). It has been suggested that marks at the enhancer could stabilize the open chromatin state to allow the AHRC-mediated transcriptional loop [27-29]. Finally, this AHR-dependent pathway has target genes such as CYP1A1, CYP1A2, and CYP1B1 and aldehyde dehydrogenase 3A1 (ALDH3A1) [30, 31]. Figure 2 shows some regulatory mechanisms involved in CYP1A1 regulation.

A number of pathways also modulate CYP1A1 transcription through binding to the promoter, interactions with AHR, or both mechanisms. Next, we briefly describe some of them.

The canonical Wnt/ $\beta$-catenin signaling pathway is involved in the adult tissue homeostasis regulation, embryonic development, and tumorigenesis. It has also been implicated in the induction of some CYPs, including mCypla1. In mice, this was demonstrated by the specific loss of CTNNB1 that encodes $\beta$-catenin and leads to a decrease of mCypla1 induction by AHR agonists such as 3-methylcholanthrene (3-MC), $\beta$-naphthoflavone $(\beta-N F)$, and butylated hydroxyanisole. Additionally, it has been observed that maximum $m$ Cyplal induction was obtained when $\beta$-catenin acted as coactivator of AHR, although this protein also binds to the transcription factor TCF, which has a binding site in mCypla1 promoter, suggesting a different mode of action [32-34]. Similarly, in rat hepatoma, it has been observed that the interaction between AHR and hypophosphorylated retinoblastoma protein $(\mathrm{pRb})$ aids maximum induction of rat CYP1A1 by 2.3, 7.8 tetrachlorodibenzo-p-dioxin (TCDD); $\mathrm{pRb}$ plays an important role in cell cycle control and it has been proposed that it could also act as a coactivator of AHR $[35,36]$.

Furthermore, several nuclear receptors are involved in the upregulation of $h C Y P 1 A 1$; for example, the constitutive androstane receptor (CAR) [37] which is also a regulator of the expression of the CYP2A, 2B, 2C, and $3 \mathrm{~A}$ subfamilies is activated by drugs; the liver $\mathrm{X}$ receptor $\alpha(\operatorname{LXR} \alpha)$ that 


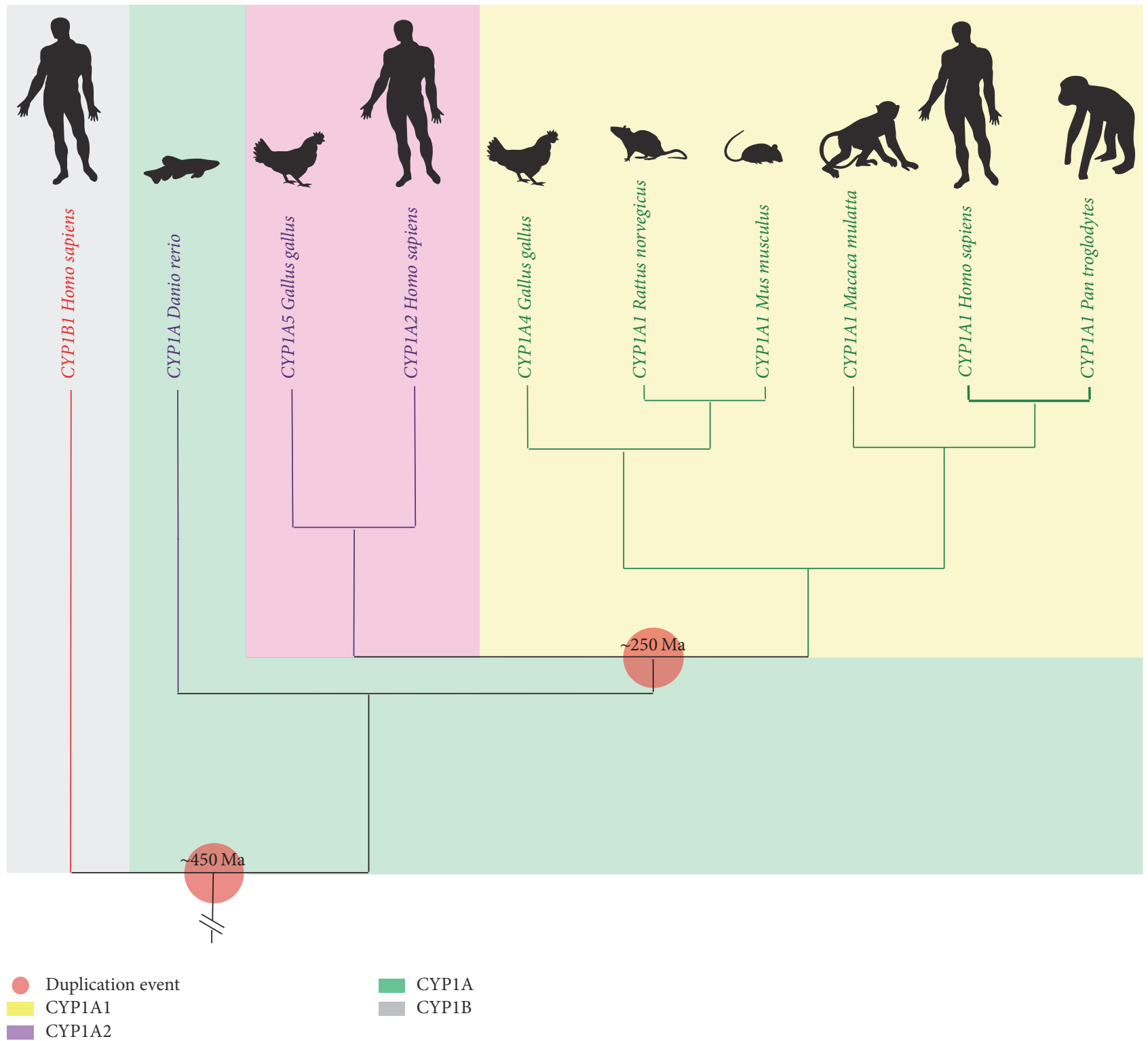

FIGURE 1: Phylogenetic tree of CYP1A subfamily through different species to human. Amino acid sequences and accession numbers of different species CYP were obtained from the Uniprot database, and with them phylogenetic tree was built in phyloT: a tree generator and visualized with ITOL v3 Interactive Tree Of Life. Silhouettes, background colors, and symbols were added to the image using Adobe Illustrator CC 2015.0.0 program.

is involved in lipid homeostasis is activated by oxysterols $[38,39]$; and the peroxisome proliferator-activated receptor $\alpha(\operatorname{PPAR} \alpha)$, is activated by fibrates, phthalates, arachidonic acid, and its derivatives $[40,41]$. These receptors bind to their specific responsive elements located in the gene promoter, activate the transcription, and potentiate the induction of hCYP1A1. The crosstalk amongst signaling pathways involved in regulating the expression of CYP1A1 could have implications for drug-drug, drug-toxic, and drug-food interactions.

\section{Downregulation of CYP1A1}

The tight regulation of CYP1A1 is highly necessary due to the known harmful effects of electrophilic compounds produced by the enzymatic activity of CYP1A1; a number of CYP1A1 downregulation mechanisms have been described; for example, the AHR repressor protein (AHRR) is a target gen of the transcriptional activity of AHR and competes with AHR for binding to XREs. AHRR has been described as a negative tissue-specific regulator of $m C Y P 1 A 1$ expression $[43,44]$. Its overexpression in transgenic mice suppresses the $m C Y P 1 A 1$ induction in lung, spleen, and adipose tissue [45]. Moreover, it has been suggested that rat CYP1A1 regulates its own expression because it catalyzes the removal of AHR agonists and thus decreases the activation of this pathway $[46,47]$.

Hypoxia inducible factor participates as a negative regulator of $h C Y P 1 A 1$ expression through the competition with AHR for the binding to ARNT. Under hypoxia conditions, 

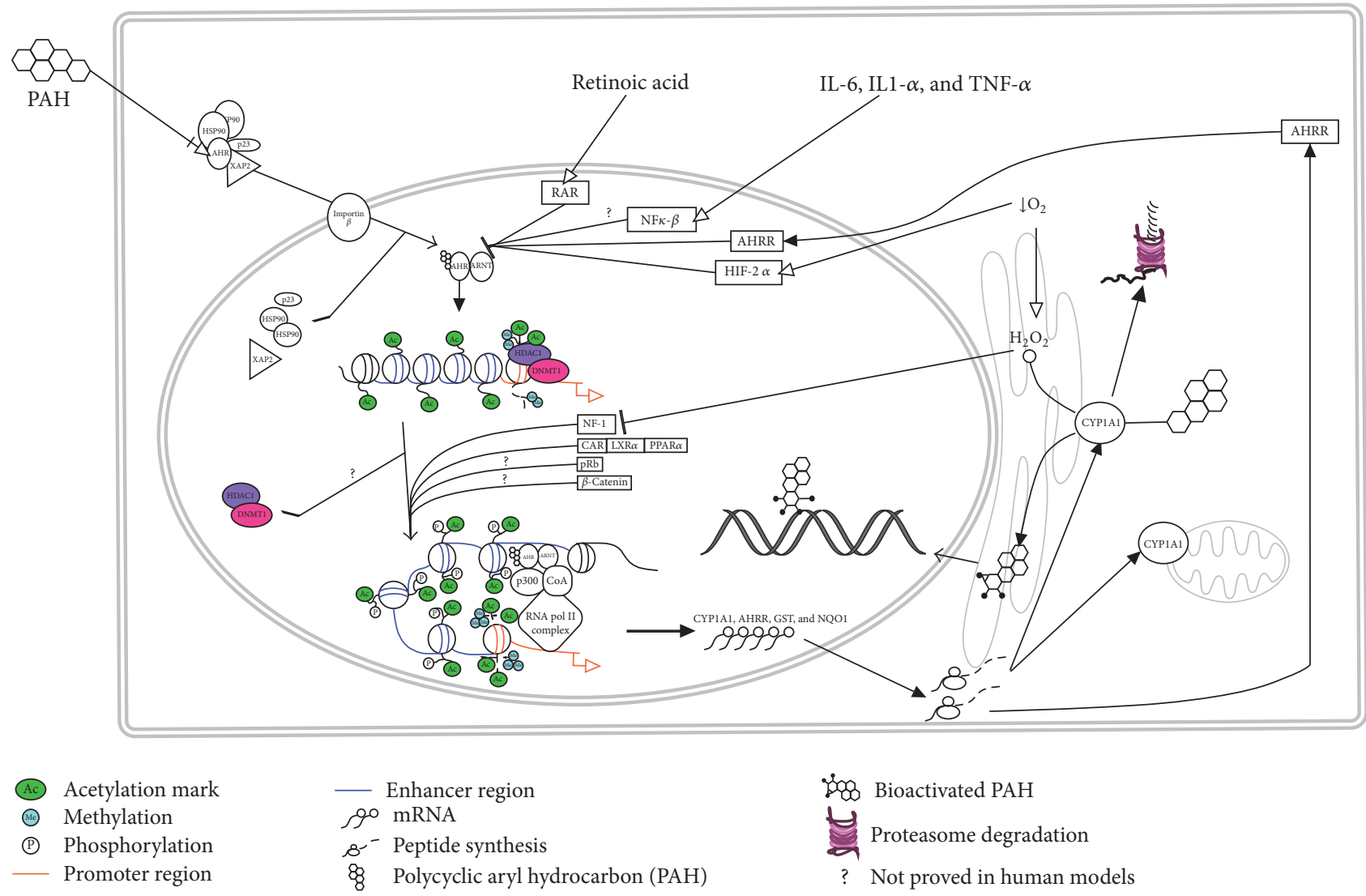

FIGURE 2: Mechanisms involved in the CYP1A1 regulation. Pathways implicated in up- and downregulation of CYP1A1 are shown, as well as changes in epigenetic marks upon the induction of this gene. The "?" symbol means pathways that had not been proved in human models, specified along the text. Image was created using PathVisio program [42] and edited with Adobe Illustrator CC 2015.0.0 program.

basal $h$ CYP1Al expression decreases [48] and induction by AHR ligands is inhibited $[49,50]$.

Moreover, the retinoic acid receptor pathway (RAR) is also implicated in the regulation of $h C Y P 1 A 1$ expression through two mechanisms. In the first one, RAR modulates the transcriptional expression of this protein through its binding to a retinoic acid responsive element (RARE) located in the $h C Y P 1 A 1$ promoter $[51,52]$. In the second one, the corepressor SMRT (silencing mediator for retinoid and thyroid receptors), which is attached to RAR, is released upon activation of RAR by retinoic acid; subsequently released SMRT can interact with AHR and reduce $h C Y P 1 A 1$ induction [53].

Another protein involved in the downregulation of $h C Y P 1 A 1$ induction is the nuclear factor I (NFI). NFI activates the expression by binding to promoter of $h C Y P 1 A 1$ and it is sensitive to oxidative stress [54]. It has been demonstrated that increased activity of hCYP1A1 generates reactive oxygen species, which in turn can lead to the oxidation of the single cysteine residue on NFI and then it is released from the $h C Y P 1 A 1$ promoter, thus decreasing the expression of this gene $[55,56]$.

The presence of a glucocorticoid responsive element in the intron one of the CYP1A1 gene in several species has been reported. The activity of the glucocorticoid receptor potentiates the effect of activated AHR in rat hepatocytes unlike human hepatocytes where dexamethasone (glucocorticoid analog) decreases the $h C Y P 1 A 1$ protein but not mRNA induced by $3-\mathrm{MC}[57,58]$. However, additional studies are needed to clarify the effect of glucocorticoids on CYP1A1 gene and protein levels.

Gut-enriched Kruppel like factor (KLFG or KLF4) is a regulator of cell proliferation, differentiation, apoptosis, and cellular reprogramming and has been identified as a negative regulator of rat CYP1A1 transcription in a dependent way of its binding to the basic transcription element (BTE); moreover, this effect might also be part of the interaction between KLFG and Sp1, an CYP1A1 transcriptional activator [59].

Another kind of downregulation is through the action of proinflammatory cytokines IL- $1 \beta$ and IL- 6 , TNF- $\alpha$, and lipopolysaccharides; these cytokines decrease constitutive CYP1A1 expression and AHR-mediated induction in human and mouse hepatocytes [60-64].

\section{Epigenetic, Posttranscriptional, and Posttranslational Regulation of CYP1A1}

Until now, several modes of action have been reported for the regulation of human CYP1A1. In essence, transcriptional expression has been reviewed, but there is another kind of gene regulation that involves epigenetic mechanisms 
such as methylation, acetylation, histone ubiquitination, or DNA methylation and hydroxylation. In this regard, to explore the role of these mechanisms on the regulation of $h$ CYP1A1 expression studies were conducted using the DNMTs inhibitor, 5-aza-2-deoxycytidine (5AzadC), and HDACs inhibitors, trichostatin A (TSA) and sodium butyrate. Table 1 summarizes the effects of these inhibitors on CYP1A1 expression. Such effects are species-specific and depend on whether the tissue is derived from healthy or cancerous donations. This review focuses mainly on hCYP1A1 regulation and just on enriching the data presented; Table 1 shows results from studies conducted in human, mouse, or rat cell lines primary cultures.

According to the results it is not possible to conclude whether $h$ CYP1A1 has a DNA methylation dependence regulation or not. It seems that tissue and temporal issues might have been involved in this regard as well as the tumor state. We cannot rule this, but tumor or cancer state allows an increased DNA methylation in $h C Y P 1 A 1$ regulatory region, at least in prostate [27] and lung [65, 69]; thus, in these models this gene has no constitutive expression which is activated by exposition to 5AzadC.

There is another type of $h C Y P 1 A 1$ regulation, which is through posttranscriptional modulation. Some in silico studies have been conducted in order to determine a possible regulation of CYP1A through noncoding RNAs. Based on web databases analyses, six putative micro RNAs (miRNAs), hsa-miR-125b-2, hsa-miR-488, hsa-miR-657, hsa-miR-892a, hsa-miR-511, and hsa-miR-626, with one or more binding sites to the $3^{\prime}$ UTR region of $h C Y P 1 A 1$ were identified [21]. Following the same strategy, an additional study used five different bioinformatics programs and predicted 332 miRNAs to target $h$ CYP1A1 UTRs, from which $12 \%$ were predicted in at least 2 programs [110].

Interestingly, in a study performed in human breast cancer cell line MCF-7 exposed to BaP leads to diminish miR-892a expression and function. This miRNA binds to 515535 nucleotides of $3^{\prime}$-UTR of human CYP1A1 and acts as translational repressor of this transcript. The putative effect of miR-892a was previously predicted by an in silico study [111]. Another study conducted in normal human liver tissues $(n=92)$ searched for a correlation between the protein level of CYP1A1 and the expression of miRs and a negative correlation was found for miR-200a $\left(r_{s}=-0.36\right)$, miR-142$3 \mathrm{p}\left(r_{s}=-0.36\right)$, and miR-200b $\left(r_{s}=-0.36\right)$ [112]. Nevertheless, another study with healthy human liver tissues from individuals of different ages determined that upregulation of miR-125b-5p was related to downregulation of CYP1A1 from fetal and pediatric samples. The effect of this miRNA was also previously predicted [113].

At this point we realize that the protein expression of CYP1A1 is tissue-, health- and age-specific; thus, it is not strange to expect that also the mechanisms and factors involved in its expression would be specific as we can observe from the previous data where two miRNAs were predicted in silico and confirmed in vivo, but none of them were found repeatedly among the studies reviewed here. It would be obvious that if there are differences in miRNAs found among results with human CYP1A1, there could be much more differences between human and other species models. This assumption is supported by a report conducted in mice fetal thymocytes where miR-31 was found as a negative regulator of $m$ Cyplal translation after exposition of cells to TCDD. Furthermore, miR-31 has matched with $3^{\prime}$-UTR of the transcript of this protein [114].

There are some studies reporting indirect regulation of CYP1A1 through the regulation of AHR by small noncoding RNAs, as in the case of the Sprague-Dawley rats treated during 2 weeks with an antagonist of the corticotrophin releasing factor I. Results show that rat liver CYP1A1 expression was increased through an atypical pathway different from AHR ligand and suggest the involvement of miR-29a-5p, miR-680, and miR-700 which were negatively expressed 10-, 6- and 8.6fold, respectively. Whether these miRNAs could act through rCYP1A1 direct binding or not is still unknown because the first two had binding sites in the $3^{\prime}$-UTR region of both rCYP1A1 and AHR [115]. More information about hCYP1A1 regulation through its $3^{\prime} \mathrm{UTR}$ region shall be discovered in the near future to achieve this objective; also more tissues and health conditions are needed to be studied.

Until this point we covered evolutionary origin of CYP1A1 and its transcriptional and posttranscriptional regulation, but once the CYP1A1 protein is formed its cellular lifetime is regulated too. The half-life time of this protein is of $\sim 2.8$ hours; this suggests a mechanism of protein degradation and the studies prompted to proteasomal degradation pathway. In fact, treatment with ubiquitin-proteasome inhibitor MG132 keeps the levels of CYP1A1, while lysosomal inhibitors do not [116-118]. In spite of these experiments, there are no reports that could help us figure out the mechanism of degradation of CYP1A1.

Another possible regulation of CYP1A1 is through the degradation of its heme group, which has been explored in human hepatoma cell line HepG2 exposed to different heavy metals. Here an increase in hemooxygenase 1 was found; this enzyme is involved in the metabolism of the heme group. Its increased levels found after heavy metals exposition correlate with diminished activity of CYP1A1, while protein level and gene expression remain unchanged $[117,119,120]$.

\section{Structural Characteristics of Human CYP1A1 and Its Ligands}

Human CYP1A1 has a molecular weight of $58.16 \mathrm{kDa}$ and consists of 512 amino acids of which the first thirty of the Nterminal region allow the association of the protein with the mitochondrial membrane and the disordered region of the smooth endoplasmic reticulum rich in unsaturated fatty acids, unlike the human CYP1A2 which is located in the sorted regions rich in cholesterol, sphingomyelin, and saturated fatty acids. Moreover, these thirty residues would also be mediating the interaction with NADPH-CYP reductase [121124].

Directed mutagenesis in the residues of the human protein showed altered kinetic parameters and demonstrates the importance of certain amino acids like Phe123, Phe224, Glu256, Asp313, Gly316, Ala317, Thr321, Val382, and Ile386 (Table 2) in the recognition, binding, and affinity for the 
TABLE 1: Effect of DNA methyltransferases and histone deacetylases inhibition on CYP1A1 expression.

\begin{tabular}{|c|c|c|c|c|c|}
\hline $\begin{array}{l}\text { DNMT inhibitor dosing } \\
\text { schedule }\end{array}$ & Cell type or specie & PAH type & Effect & DNA methylation status & Source \\
\hline & $\begin{array}{c}\text { Human cell } \\
\text { adenocarcinoma, } \\
\text { A549 } \\
\text { Human bronchial } \\
\text { epithelium cell } \\
\text { line, Beas-2B } \\
\end{array}$ & $\begin{array}{c}\mathrm{BaP} 1 \mathrm{nM}, 100 \mathrm{nM} \text {, and } \\
10 \mathrm{uM}\end{array}$ & $\begin{array}{c}\text { hCYP1A1 expression started } \\
\text { with } 10 \mu \mathrm{M} \text {. } \\
\text { hCYP1A1 expression started } \\
\text { with } 100 \mathrm{nM} \text {. }\end{array}$ & $\begin{array}{l}35 \% \text { complete } \\
\text { methylation } \\
11 \% \text { complete } \\
\text { methylation. }\end{array}$ & {$[65]$} \\
\hline 5 AzadC, 5 uM, $96 \mathrm{~h}$ & $\begin{array}{l}\text { Human breast } \\
\text { carcinoma cell line, } \\
\text { MCF-7 } \\
\text { Human cervical } \\
\text { adenocarcinoma } \\
\text { cell line, HeLa }\end{array}$ & 10 nM TCDD lasts 24 hours & $\begin{array}{c}\text { hCYP1A1 expression } \\
\text { increased 2-3-fold in Aza } \\
\text { versus ctrl but did not } \\
\text { change in Aza-TCDD } \\
\text { versus TCDD. } \\
\text { hCYP1A1 expression } \\
\text { increased } 4 \text {-fold in Aza } \\
\text { versus ctrl and 7-fold in } \\
\text { Aza-TCDD versus ctrl. }\end{array}$ & $\begin{array}{l}\text { Both cell lines: highly } \\
\text { methylated at CpG sites } \\
\text { in enhancer region. Low } \\
\text { methylated at CpG sites } \\
\text { in promoter region. }\end{array}$ & {$[66]$} \\
\hline $\begin{array}{l}5 \mathrm{AzadC}, 0,0.25 \text {, and } \\
1 \mathrm{uM}\end{array}$ & $\begin{array}{c}\text { Human prostatic } \\
\text { epithelial cell line, } \\
\text { PWR1-E } \\
\text { Human prostatic } \\
\text { epithelial cell line, } \\
\text { RWPE-1 } \\
\text { Human prostate } \\
\text { adenocarcinoma } \\
\text { cell line, LNCaP }\end{array}$ & TCDD, $10 \mathrm{nM}$ & $\begin{array}{l}h C Y P 1 A 1 \text { expression } \\
\text { increased in both PWR1 } \\
\text { and RWPE1 treated with } \\
\text { AzadC but not in the } \\
\text { induction by TCDD. } \\
\text { LNCaP increased their } \\
\text { hCYP1A1 induction by } \\
\text { TCDD in a dose } \\
\text { dependence of AzadC }\end{array}$ & $\begin{array}{l}\text { RWP1 low methylated } \\
\text { than LNCaP at enhancer } \\
\text { region. No methylation } \\
\text { at promoter. }\end{array}$ & {$[27]$} \\
\hline $\begin{array}{l}\text { 5AzadC, } 2 \text { uM, } 72 \text { h } \\
\text { (each } 12 \mathrm{~h})\end{array}$ & $\begin{array}{l}\text { Mouse hepatoma } \\
\text { cell line, Hepalclc7 }\end{array}$ & $5 \mathrm{uM} \mathrm{BaP}, 8 \mathrm{~h}$ & $\begin{array}{c}\text { Aza does not change } \\
m C Y P 1 A 1 \text { expression versus } \\
\text { control } \\
\text { Aza-BaP does not change } \\
\text { mCyplal induction versus } \\
\text { BaP } \\
\end{array}$ & ND & {$[28]$} \\
\hline 5AzadC, 5 uM, 3 days & $\begin{array}{l}\text { Mouse hepatoma } \\
\text { cell line, Hepalclc7 } \\
\text { Mouse embryonic } \\
\text { fibroblast, } \\
\text { C3H10T1/2 }\end{array}$ & $10 \mathrm{nM}$ TCDD, $48 \mathrm{~h}$ & $\begin{array}{c}\text { Nonincrease mCypla1 } \\
\text { expression in Aza-TCDD } \\
\text { induced versus TCDD. } \\
\text { C3H10T1: } m C y p 1 a 1 \\
\text { expression increased in } \\
\text { Aza-TCDD induced versus } \\
\text { TCDD. }\end{array}$ & ND & {$[67]$} \\
\hline 5AzadC, 5 uM, 72 h & $\begin{array}{c}\text { Human breast } \\
\text { cancer cell line, } \\
\text { MCF7 } \\
\text { Human hepatic } \\
\text { cancer cell line, } \\
\text { HepG2 }\end{array}$ & $\begin{array}{l}\text { TCDD last } 24 \mathrm{~h} \text { of } 5 \mathrm{AzadC} \\
\text { treatment }\end{array}$ & $\begin{array}{l}\text { MCF7, no differences. } \\
\text { HepaG2. no differences. }\end{array}$ & ND & {$[29]$} \\
\hline $\begin{array}{l}5 \text { AzadC } 1,5,10,50,250, \\
\text { and } 500 \mathrm{uM}, 72 \text { hours } \\
\text { after EGF treatment }\end{array}$ & $\begin{array}{c}\text { Primary rat } \\
\text { hepatocytes } \\
\text { (Sprague-Dawley } \\
\text { rats) }\end{array}$ & & $\begin{array}{c}\text { rCYP1A1 protein increases } \\
\text { in dose dependence of } \\
\text { AzadC }\end{array}$ & ND & {$[68]$} \\
\hline 5AzadC, 0.5 uM, 5 days & $\begin{array}{l}\text { Primary normal } \\
\text { human bronchial } \\
\text { epithelial cells, } \\
\text { NHBE }(n=12) \text {. } \\
\text { Human bronchial } \\
\text { epithelial cell lines } \\
\text { (HBEC } n=3) \text {. } \\
\text { Human lung } \\
\text { adenocarcinoma } \\
\text { cell lines (HLAC } \\
n=9)\end{array}$ & & $\begin{array}{l}\text { AzadC increased } h C Y P 1 A 1 \\
\text { expression in HLAC }\end{array}$ & $\begin{array}{l}\text { NHBE and HBEC were } \\
\text { low methylated than } \\
\text { HLAC at enhancer } \\
\text { region. }\end{array}$ & {$[69]$} \\
\hline
\end{tabular}


TABLE 1: Continued.

\begin{tabular}{|c|c|c|c|c|c|}
\hline $\begin{array}{l}\text { DNMT inhibitor dosing } \\
\text { schedule }\end{array}$ & Cell type or specie & PAH type & Effect & DNA methylation status & Source \\
\hline $\begin{array}{l}\text { 5AzadC, } 5 \text { uM, } 7 \text { days } \\
\text { (with culture media } \\
\text { changed on day four). } \\
\text { On day } 6 \text { cells were split } \\
\text { into } 60 \text { mm dishes in } \\
\text { culture media with } \\
\text { AzadC. Day 7, media } \\
\text { were changed. }\end{array}$ & $\begin{array}{l}\text { Human cervical } \\
\text { adenocarcinoma } \\
\text { cell line, HeLa }\end{array}$ & & $\begin{array}{l}\text { AzadC increased } h C Y P 1 A 1 \\
\text { expression versus ctrl. }\end{array}$ & $\begin{array}{l}\text { HeLa and HepG2 were } \\
\text { equally methylated at } \\
\text { promoter. }\end{array}$ & {$[70]$} \\
\hline $\begin{array}{l}5 \text { AzadC, } 5 \mu \mathrm{M}, 5 \text { days } \\
5 \mu \mathrm{M} \text { RG108, } 5 \text { days }\end{array}$ & $\begin{array}{l}\text { Human primary } \\
\text { hepatocytes (hPH) } \\
\text { Human embryonic } \\
\text { stem cells derived } \\
\text { hepatocytes } \\
\text { (hESC.Hep) }\end{array}$ & & $\begin{array}{l}\text { hESC-Hep: increased } \\
\text { hCYP1A1 expression in } \\
\text { both 5AzadC and RG108 } \\
\text { treatments. }\end{array}$ & $\begin{array}{l}\text { hPH: no methylated } \\
\text { hESC-Hep: high } \\
\text { methylated. }\end{array}$ & {$[71]$} \\
\hline $\begin{array}{l}\text { HDAC inhibitor dosing } \\
\text { schedule }\end{array}$ & Cell line type & AHR ligand & \multicolumn{2}{|c|}{ Effect } & Source \\
\hline $\begin{array}{l}\text { TSA }(200 \mathrm{ng} / \mathrm{mL}) \\
30 \text { min prior to TCDD }\end{array}$ & $\begin{array}{l}\text { Mouse hepatoma } \\
\text { cell line, Hepalclc7 }\end{array}$ & TCDD, $1 \mathrm{pM}$ & \multicolumn{2}{|c|}{$\begin{array}{c}\text { No effect on EROD basal enzyme activity } \\
\text { Increased TCDD, concentration dependence } \\
\text { induction of EROD enzyme activity and CYP1A1 } \\
\text { protein }\end{array}$} & {$[72]$} \\
\hline TSA, $100 \mathrm{ng} / \mathrm{mL}, 24 \mathrm{~h}$ & $\begin{array}{l}\text { Human breast } \\
\text { carcinoma cell line, } \\
\text { MCF-7 } \\
\text { Human cervical } \\
\text { adenocarcinoma } \\
\text { cell line, HeLa } \\
\end{array}$ & $\begin{array}{l}\text { TCDD } 10 \mathrm{nM} \text { (after TSA) } \\
24 \mathrm{~h}\end{array}$ & \multicolumn{2}{|c|}{$\begin{array}{c}\text { Increased basal } h C Y P 1 A 1 \text { expression, but TSA had } \\
\text { no effect on TCDD induced mRNA. } \\
\text { Increased basal and TCDD induced } h C Y P 1 A 1 \text { mRNA }\end{array}$} & {$[66]$} \\
\hline $\begin{array}{l}\text { SAHA }(0.2-4.0 \mu \mathrm{M}), 12 \\
\text { and } 24 \mathrm{~h} \\
\text { TSA }(0.2-4.0 \mu \mathrm{M}), 12 \\
\text { and } 24 \mathrm{~h}\end{array}$ & $\begin{array}{l}\text { Human breast } \\
\text { carcinoma cell line, } \\
\text { MCF-7 }\end{array}$ & $\mathrm{BaP}, 4 \mu \mathrm{M}$ & \multicolumn{2}{|c|}{$\begin{array}{c}\text { Increased BaP induced EROD activity and basal } \\
h C Y P 1 A 1 \text { mRNA } \\
\text { No effects on BaP induced } h C Y P 1 A 1 \text { mRNA } \\
\text { Increased BaP induced EROD activity and basal } \\
h C Y P 1 A 1 \text { mRNA } \\
\text { Decreased BaP induced } h C Y P 1 A 1 \text { mRNA }\end{array}$} & {$[73]$} \\
\hline $\begin{array}{l}\text { TSA }(25 \mu \mathrm{M}), 2,4 \text {, and } 7 \\
\text { days }\end{array}$ & $\begin{array}{c}\text { Primary rat } \\
\text { hepatocytes } \\
\text { (Sprague Dawley) }\end{array}$ & None & \multicolumn{2}{|c|}{$\begin{array}{c}\text { Increased EROD activity at day } 7 . \\
\text { Increased rCYP1A1 protein at all days tested. } \\
\text { Increased } r C Y P 1 A 1 \text { mRNA at days } 4 \text { and } 7 .\end{array}$} & {$[74]$} \\
\hline $\begin{array}{l}\text { Sodium butyrate }(\mathrm{NaB}) \\
2 \mathrm{mM}, 16 \mathrm{~h}\end{array}$ & $\begin{array}{l}\text { Mouse hepatoma } \\
\text { cell line, Hepalclc7 }\end{array}$ & $\mathrm{BaP}, 5 \mu \mathrm{M}, 8 \mathrm{~h}$ & \multicolumn{2}{|c|}{ No changes on basal and induced mCypla1 mRNA } & {$[28]$} \\
\hline TSA, $100 \mathrm{nM}, 24 \mathrm{~h}$ & $\begin{array}{c}\text { Mouse hepatoma } \\
\text { cell line, Hepal-OT } \\
\text { Mouse embryonic } \\
\text { fibroblast cell line, } \\
\text { C3H10T1/2 }\end{array}$ & $\mathrm{TCDD}, 10 \mathrm{nM}, 24 \mathrm{~h}$ & \multicolumn{2}{|c|}{$\begin{array}{l}\text { Increased TCDD induced } m C y p 1 a 1 \text { mRNA } \\
\text { Increased TCDD induced } m C y p 1 a 1 \text { mRNA }\end{array}$} & {$[67]$} \\
\hline AN-8 $(1-5 \mu \mathrm{M}), 72 \mathrm{~h}$ & $\begin{array}{c}\text { Primary } \\
\text { hepatocytes culture }\end{array}$ & None & \multicolumn{2}{|c|}{ Increased CYP1A1 protein level } & {$[68]$} \\
\hline TSA $250 \mathrm{nM}, 16 \mathrm{~h}$ & $\begin{array}{l}\text { Human cervical } \\
\text { adenocarcinoma } \\
\text { cell line, HeLa }\end{array}$ & $\begin{array}{c}\text { PCB, } 1363 \mu \mathrm{M} \text { (after TSA), } \\
6 \mathrm{~h}\end{array}$ & \multicolumn{2}{|c|}{ Increased basal and PCB induced $h C Y P 1 A 1 \mathrm{mRNA}$} & {$[70]$} \\
\hline
\end{tabular}

ND: nondetermined. All increases or decreases in DNA methylation, mRNA, or protein were significantly different with respect to the respective control. For more information about this, references to the original work are provided.

EROD: Ethoxyresorufin O-deethylation CYP1A1 enzyme activity.

substrates. However, the spatial orientation of these residues was known until the three-dimensional structure of human CYP1A1 was resolved by X-ray crystallography at a resolution of $2.6 \AA[125]$.
The protein crystallization of human CYP1A1 allowed us to know that this protein is comprised by twelve $\alpha$-helices (A$L)$, three $\beta$-sheets $(\beta 1-\beta 3)$, and four helical short regions $\left(A^{\prime}\right.$, $\mathrm{B}^{\prime}, \mathrm{F}^{\prime}$, and $\left.\mathrm{G}^{\prime}\right)$ forming six sequences as putative substrate 
TABLE 2: Effect of mutations in the amino acid sequence of human CYP1A1 on the kinetic parameters of this enzyme.

\begin{tabular}{|c|c|c|c|c|c|c|}
\hline Amino acid & Position & Amino acid type & Mutation & Amino acid type & Effect & Reference \\
\hline Gly & $\begin{array}{c}45 \\
\text { loop } A^{\prime}\end{array}$ & $\begin{array}{l}\text { Nonpolar, } \\
\text { aliphatic }\end{array}$ & Asp & Negatively charged & $\begin{array}{c}K_{m} \text { and } V_{\max } \text { are } \\
\text { decreased by } 42.9 \% \text { and } \\
75.1 \% \text {, respectively }\end{array}$ & {$[75]$} \\
\hline Ala & $\begin{array}{c}62 \\
\text { helix A }\end{array}$ & $\begin{array}{l}\text { Nonpolar, } \\
\text { aliphatic }\end{array}$ & Pro & Nonpolar, aliphatic & $\begin{array}{l}K_{m} \text { is increased by } 84 \% \\
\text { and } V_{\max } \text { is decreased by } \\
21 \%\end{array}$ & {$[76]$} \\
\hline Ser & $\begin{array}{c}116 \\
\text { helix B }\end{array}$ & $\begin{array}{c}\text { Polar, } \\
\text { uncharged }\end{array}$ & Ala & Nonpolar, aliphatic & $\begin{array}{c}K_{m} \text { and } V_{\max } \text { do not } \\
\text { change }\end{array}$ & {$[77]$} \\
\hline \multirow[b]{2}{*}{ Ser } & \multirow{2}{*}{$\begin{array}{c}122 \\
\text { loop } B^{\prime}-C\end{array}$} & \multirow{2}{*}{$\begin{array}{c}\text { Polar, } \\
\text { uncharged }\end{array}$} & Thr & Polar, uncharged & $\begin{array}{l}\text { Activity is increased by } \\
25 \%\end{array}$ & {$[78]$} \\
\hline & & & Ala & Nonpolar, aliphatic & $\begin{array}{c}K_{m} \text { and } V_{\max } \text { are } \\
\text { increased by } 74 \% \text { and } \\
\text { 2-fold, respectively }\end{array}$ & {$[79]$} \\
\hline Phe & $\begin{array}{c}123 \\
\text { loop } B^{\prime}-C\end{array}$ & Aromatic & Ala & Nonpolar, aliphatic & $\begin{array}{c}\text { Without activity. } \\
K_{m} \text { is increased by } \\
12.8 \text {-fold and } V_{\max } \text { is } \\
\text { decreased by } 42.5 \%\end{array}$ & {$[77,79]$} \\
\hline Glu & $\begin{array}{c}161 \\
\text { helix D }\end{array}$ & $\begin{array}{l}\text { Negatively } \\
\text { charged }\end{array}$ & Lys & Positively charged & $\begin{array}{c}K_{m} \text { is decreased by } 39 \% \\
\text { and } V_{\max } \text { does not } \\
\text { change }\end{array}$ & {$[77]$} \\
\hline Glu & $\begin{array}{c}166 \\
\text { helix D }\end{array}$ & $\begin{array}{l}\text { Negatively } \\
\text { charged }\end{array}$ & Gln & Nonpolar, aliphatic & $\begin{array}{c}K_{m} \text { and } V_{\max } \text { are } \\
\text { increased by } 3.7 \text {-fold and } \\
24 \% \text {, respectively }\end{array}$ & {$[77]$} \\
\hline Val & $\begin{array}{c}191 \\
\text { helix E }\end{array}$ & $\begin{array}{l}\text { Nonpolar, } \\
\text { aliphatic }\end{array}$ & Met & Polar, uncharged & $\begin{array}{c}K_{m} \text { and } V_{\max } \text { do not } \\
\text { change }\end{array}$ & {$[77]$} \\
\hline Asn & $\begin{array}{c}221 \\
\text { helix F }\end{array}$ & $\begin{array}{l}\text { Nonpolar, } \\
\text { aliphatic }\end{array}$ & Thr & Polar, uncharged & $\begin{array}{l}\text { Activity is decreased to } \\
28 \%\end{array}$ & {$[78]$} \\
\hline Phe & $\begin{array}{c}224 \\
\text { helix F }\end{array}$ & Aromatic & Ala & Nonpolar, aliphatic & $\begin{array}{c}V_{\max } \text { and } K_{m} \text { are } \\
\text { decreased by } 11.4 \text {-fold } \\
\text { and } 75 \% \text {, respectively }\end{array}$ & {$[79]$} \\
\hline Gly & $\begin{array}{c}225 \\
\text { helix F } \\
\end{array}$ & $\begin{array}{l}\text { Nonpolar, } \\
\text { aliphatic }\end{array}$ & Val & Nonpolar, aliphatic & $\begin{array}{c}\text { Activity is decreased to } \\
19 \%\end{array}$ & {$[78]$} \\
\hline Val & $\begin{array}{c}228 \\
\text { helix F } \\
\end{array}$ & $\begin{array}{l}\text { Nonpolar, } \\
\text { aliphatic }\end{array}$ & Thr & Polar, uncharged & $\begin{array}{c}K_{m} \text { and } V_{\max } \text { do not } \\
\text { change }\end{array}$ & {$[77]$} \\
\hline Glu & $\begin{array}{c}256 \\
\text { helix G }\end{array}$ & $\begin{array}{l}\text { Negatively } \\
\text { charged }\end{array}$ & Lys & Positively charged & $\begin{array}{c}K_{m} \text { is decreased by } 70 \% \\
\text { and } V_{\max } \text { does not } \\
\text { change }\end{array}$ & {$[77]$} \\
\hline Tyr & $\begin{array}{c}259 \\
\text { helix G }\end{array}$ & Aromatic & Phe & Aromatic & $\begin{array}{c}K_{m} \text { is increased by } \\
2.7 \text {-fold and } V_{\max } \text { does } \\
\text { not change }\end{array}$ & {$[77]$} \\
\hline Asn & $\begin{array}{c}309 \\
\text { helix H }\end{array}$ & $\begin{array}{l}\text { Nonpolar, } \\
\text { aliphatic }\end{array}$ & Thr & Polar, uncharged & $\begin{array}{c}K_{m} \text { and } V_{\max } \text { do not } \\
\text { change }\end{array}$ & {$[77]$} \\
\hline \multirow{2}{*}{ Leu } & \multirow{2}{*}{$\begin{array}{c}312 \\
\text { helix I }\end{array}$} & \multirow{2}{*}{$\begin{array}{l}\text { Nonpolar, } \\
\text { aliphatic }\end{array}$} & Asn & Nonpolar, aliphatic & $\begin{array}{c}\text { Activity is decreased to } \\
42 \%\end{array}$ & {$[78]$} \\
\hline & & & Phe & Aromatic & $\begin{array}{c}K_{m} \text { is increased by } 89 \% \\
\text { and } V_{\max } \text { does not } \\
\text { change }\end{array}$ & {$[77]$} \\
\hline \multirow{2}{*}{ Asp } & \multirow{2}{*}{$\begin{array}{c}313 \\
\text { helix I }\end{array}$} & \multirow{2}{*}{$\begin{array}{l}\text { Negatively } \\
\text { charged }\end{array}$} & Ala & Nonpolar, aliphatic & $\begin{array}{c}K_{m} \text { and } V_{\max } \text { are } \\
\text { increased by } 21 \text {-fold and } \\
28 \% \text {, respectively }\end{array}$ & {$[77]$} \\
\hline & & & Asn & Nonpolar, aliphatic & $\begin{array}{c}K_{m} \text { is increased by } \\
24.5 \text {-fold and } V_{\max } \text { is } \\
\text { decreased by } 37.5 \%\end{array}$ & {$[77]$} \\
\hline Gly & $\begin{array}{c}316 \\
\text { helix I }\end{array}$ & $\begin{array}{l}\text { Nonpolar, } \\
\text { aliphatic }\end{array}$ & Val & Nonpolar, aliphatic & $\begin{array}{l}K_{m} \text { is increased by } \\
17 \text {-fold and } V_{\max } \text { is } \\
\text { decreased by } 30 \%\end{array}$ & {$[77]$} \\
\hline
\end{tabular}


TABLE 2: Continued.

\begin{tabular}{|c|c|c|c|c|c|c|}
\hline Amino acid & Position & Amino acid type & Mutation & Amino acid type & Effect & Reference \\
\hline \multirow[b]{2}{*}{ Ala } & \multirow[b]{2}{*}{$\begin{array}{c}317 \\
\text { helix I }\end{array}$} & \multirow[b]{2}{*}{$\begin{array}{l}\text { Nonpolar, } \\
\text { aliphatic }\end{array}$} & Tyr & Aromatic & Without activity & [79] \\
\hline & & & Gly & Nonpolar, aliphatic & $\begin{array}{c}K_{m} \text { is increased by } \\
30 \text {-fold and } V_{\max } \text { is } \\
\text { decreased by } 25 \%\end{array}$ & [77] \\
\hline Asp & $\begin{array}{c}320 \\
\text { helix I }\end{array}$ & $\begin{array}{l}\text { Negatively } \\
\text { charged }\end{array}$ & Ala & Nonpolar, aliphatic & $\begin{array}{l}K_{m} \text { is increased by } \\
2.7 \text {-fold and } V_{\max } \text { is } \\
\text { decreased by } 35 \%\end{array}$ & {$[77]$} \\
\hline \multirow{3}{*}{ Thr } & \multirow{3}{*}{$\begin{array}{c}321 \\
\text { helix I }\end{array}$} & \multirow{3}{*}{$\begin{array}{c}\text { Polar, } \\
\text { uncharged }\end{array}$} & Gly & Nonpolar, aliphatic & $\begin{array}{c}K_{m} \text { is increased by } 30 \% \\
\text { and } V_{\max } \text { is decreased by } \\
70 \%\end{array}$ & [79] \\
\hline & & & Pro & Nonpolar, aliphatic & $\begin{array}{c}K_{m} \text { is increased by } \\
6.2 \text {-fold and } V_{\max } \text { does } \\
\text { not change }\end{array}$ & {$[77]$} \\
\hline & & & Ser & Polar, uncharged & $\begin{array}{c}K_{m} \text { and } V_{\max } \text { are } \\
\text { increased by } 7.6 \text {-fold and } \\
\text { 2-fold, respectively }\end{array}$ & {$[77]$} \\
\hline Val & $\begin{array}{c}322 \\
\text { helix I }\end{array}$ & $\begin{array}{l}\text { Nonpolar, } \\
\text { aliphatic }\end{array}$ & Ala & Nonpolar, aliphatic & $\begin{array}{c}K_{m} \text { is increased by } 67 \% \\
\text { and } V_{\max } \text { does not } \\
\text { change }\end{array}$ & {$[77]$} \\
\hline \multirow{2}{*}{ Val } & \multirow{2}{*}{$\begin{array}{c}382 \\
\text { helix K/ loop } \beta 1-4\end{array}$} & \multirow{2}{*}{$\begin{array}{l}\text { Nonpolar, } \\
\text { aliphatic }\end{array}$} & Ala & Nonpolar, aliphatic & $\begin{array}{c}\text { Activity is decreased to } \\
66 \%\end{array}$ & {$[78]$} \\
\hline & & & Leu & Nonpolar, aliphatic & $\begin{array}{l}\text { Activity is decreased to } \\
7 \%\end{array}$ & {$[78]$} \\
\hline \multirow[b]{2}{*}{ Ile } & \multirow[b]{2}{*}{$\begin{array}{c}386 \\
\text { helix K/ loop } \beta 1-4\end{array}$} & \multirow[b]{2}{*}{$\begin{array}{l}\text { Nonpolar, } \\
\text { aliphatic }\end{array}$} & Gly & Nonpolar, aliphatic & Without activity & [79] \\
\hline & & & Val & Nonpolar, aliphatic & $\begin{array}{c}K_{m} \text { and } V_{\max } \text { are } \\
\text { increased by } 87 \% \text { and } \\
58 \% \text {, respectively }\end{array}$ & {$[77]$} \\
\hline \multirow{2}{*}{ Ile } & \multirow{2}{*}{$\begin{array}{c}458 \\
\text { helix L }\end{array}$} & \multirow{2}{*}{$\begin{array}{l}\text { Nonpolar, } \\
\text { aliphatic }\end{array}$} & Pro & Nonpolar, aliphatic & $\begin{array}{c}K_{m} \text { is increased by } 44 \% \\
\text { and } V_{\max } \text { does not } \\
\text { change }\end{array}$ & {$[77]$} \\
\hline & & & Val & Nonpolar, aliphatic & $\begin{array}{c}K_{m} \text { and } V_{\max } \text { are } \\
\text { decreased by } 55 \% \text { and } \\
21 \% \text {, respectively }\end{array}$ & {$[77]$} \\
\hline Thr & $\begin{array}{c}497 \\
\text { loop } \beta 4\end{array}$ & $\begin{array}{c}\text { Polar, } \\
\text { uncharged }\end{array}$ & Ser & Polar, uncharged & $\begin{array}{c}K_{m} \text { is increased by 3-fold } \\
\text { and } V_{\max } \text { does not } \\
\text { change }\end{array}$ & {$[77]$} \\
\hline
\end{tabular}

recognition sites (SRS) important for ligand selectivity of this enzyme $[125,126]$, which are shown in Figure 3 and listed as follows.

(i) SRS1 corresponds to the amino acid region 106-124 of loop between helix B and helix B' and portion of loop between helix $\mathrm{B}^{\prime}$ and helix $\mathrm{C}$. In turn, it forms part of the wall of the active site and it is proposed as a site for the input and output of ligands that influence the regioselectivity for the oxidation of substrates [127, 128].

(ii) SRS2 is part of the helices E and F, as well as of the residues 217-228, in the loop that connects these regions. Its role is similar to SRS1 participating in the ligand orientation $[129,130]$.

(iii) SRS3 is found in helix G from amino acid 251 to amino acid 262 [126]. (iv) SRS4 corresponds to helix I (residues 309-324) [126].

(v) SRS5 goes from residue 381 to residue 386 and connects helix J to the beta sheet. In other CYPs this region has been associated with the entry of the ligand due to its high flexibility [130].

(vi) SRS6 is the shortest region and is located in the loop near the $\beta 3$ sheet [126].

The human CYP1A1 structure allows binding planar molecule with $\sim 12.3 \AA$ in length and $\sim 4.6 \AA$ in width, conformed by aromatic, polyaromatic, and heterocyclic rings which are essential for the formation of $\pi-\pi$ stacking in the protein active site, mainly with Phe-224 at helix F, conferring stability to the enzyme-substrate complex [43, 80, 81, 131-135]. Nevertheless, for specific substrate redox reaction to be produced (Table 3), ligand also requires to be oriented with its reactive group facing the heme group $[136,137]$. 
TABLE 3: Reactions carried out by the human CYP1A1 depending on the type of substrate.

\begin{tabular}{|c|c|c|c|}
\hline Origin & Category compound & Type of reaction & Source \\
\hline \multirow{7}{*}{ Synthetic compounds } & Polycyclic aromatic hydrocarbons & Oxidation Epoxidation & {$[80,81]$} \\
\hline & Nitrosamides & Nitroreduction & {$[82,83]$} \\
\hline & Arylamines & $N$-hydroxylation Oxidation & {$[80,81]$} \\
\hline & Benzotriazole & Oxidation & {$[84]$} \\
\hline & Heterocyclic amines & $N$-hydroxylation Oxidation & {$[80,81]$} \\
\hline & Nitroarenes & Nitroreduction & {$[85]$} \\
\hline & Azoaromatic amines & Oxidation & {$[80,81]$} \\
\hline \multirow{3}{*}{ Natural compounds } & Difuranocumarin & Epoxidation Oxidation & {$[86]$} \\
\hline & Nefrotoxin & Hydroxylation & {$[87]$} \\
\hline & Flavonoid & Hydroxylation $O$-demethylation & {$[88,89]$} \\
\hline \multirow{3}{*}{ Drugs } & Ellipticin & Oxidation & {$[90]$} \\
\hline & Omeprazol & ND & {$[91]$} \\
\hline & Oltipraz & $\mathrm{ND}$ & [92] \\
\hline \multirow{4}{*}{ Endogenous substrates } & Arachidonic acid & Hydroxylation & {$[93]$} \\
\hline & Melatonin & Hydroxylation & {$[94]$} \\
\hline & Eicosapentaenoic acid & Epoxidation & [93] \\
\hline & Stradiol & Hydroxylation & {$[95]$} \\
\hline
\end{tabular}
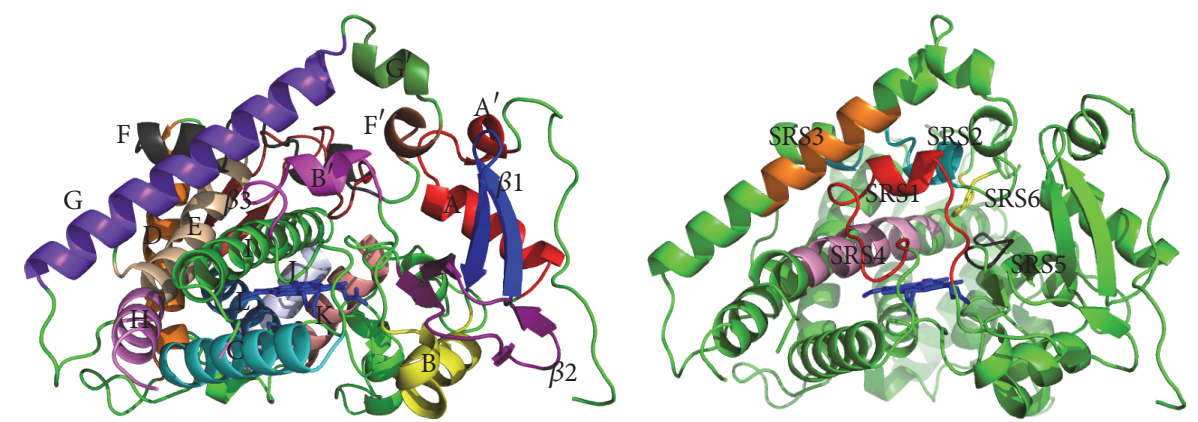

FIgURE 3: Three-dimensional structure and substrate recognition sites (SRS) of human CYP1A1. Figure was created with PyMOL Molecular Graphics System, Version 1.3 Schrödinger, LLC.

\section{CYP1A1 through Development}

Besides its importance in the metabolism of xenobiotics, CYP1A1 is also involved in the metabolism of endogenous compounds, such as arachidonic acid, eicosapentaenoic acid [93], 17 $\beta$-estradiol [95], and melatonin [94].

Arachidonic acid and eicosapentaenoic acid are biotransformed by this enzyme to products such as 14, 15-epoxyeicosatrienoic acid and 17, 18-epoxyeicosatetraenoic acid, which influence cardiovascular pressure [93]. This attribute highlighted the importance of the association between heart diseases and CYP1A1 polymorphisms [138-140].

Treatment with the CYP1A inhibitor, $\alpha$-naphthoflavone, shows that the activity of CYP1A1 is important for the proper development of the embryo's cardiovascular system [141143]. However, so far there is not enough information about the impact of this isoform in the endogenous metabolism, so it is essential to conduct more studies that can help us to understand the mechanisms of these processes and their impact on the human health.

The use of different animal models has proved that activity and basal expression of CYP1A1 during embryonic development are organ-stage-specific (Table 4), where the liver and cardiovascular tissues have the highest expression. In the chicken, exposure to CYP1A1 inducers causes an increase in heart size and weight, while, in fish, edema in pericardium as well as modifications in the normal shape of the organ has been reported [141, 142, 144-148].

Searching whether the function of CYP1A1 is crucial for life, a line of knockout mice for this gene was produced [149]. These animals show decreased liver, kidney, and heart weight, as well as increased blood pressure and lower heart rate compared to wild type mice, thus demonstrating the importance of CYP1A1 in the cardiovascular system [150].

In adulthood, the human CYP1A1 expression is low and is found particularly in tissues of the respiratory system such 
TABLE 4: Basal expression and activity of CYP1A1 in different animal models.

\begin{tabular}{|c|c|c|c|c|}
\hline Animal model & Development stage & Spatial localization & Detection method & Reference \\
\hline \multirow{3}{*}{ Human } & $16-36$ gestation weeks & Not determined- & PCR & {$[96]$} \\
\hline & $50-60$ gestation weeks & Hepatic tissue & $\begin{array}{c}\text { BZROD } \\
(\mathrm{microsomes}) \\
\left(8.8 \pm 2.1 \mathrm{pmol} / \mathrm{mg} \text { of protein } / \mathrm{min}^{-1}\right)\end{array}$ & {$[97]$} \\
\hline & 74-145 gestation days & $\begin{array}{c}\text { Day 87: kidney } \\
\text { Days 55, 70, 101, and 112: lung } \\
\text { Days } 45,70 \text {, and } 85 \text { : liver }\end{array}$ & PCR: southern blot & [98] \\
\hline \multirow[b]{2}{*}{ Mouse } & E17 & Not determined- & PCR & {$[96,99]$} \\
\hline & E7-E14 & $\begin{array}{l}\text { E7: extraembryonic ectoderm } \\
\text { and mesoderm } \\
\text { E8.5: myocardial cells in } \\
\text { ventricular chamber } \\
\text { E10: left and right heart ventricle } \\
\text { Dorsal aorta and neuroepithelial } \\
\text { cells of midbrain } \\
\text { E12: myocardial cells of both } \\
\text { heart ventricles and midbrain } \\
\text { E13: dorsal aorta, heart, and } \\
\text { epithelium of midbrain } \\
\text { E14: dorsal aorta, both heart } \\
\text { ventricles, and atrium } \\
\text { Epithelium of midbrain and } \\
\text { trigeminal ganglion. }\end{array}$ & $\begin{array}{l}\text { lacZ reporter with the promoter of } \\
\qquad C Y P 1 A 1\end{array}$ & {$[100]$} \\
\hline Rat & $15-29$ gestation days & $\begin{array}{l}\text { D15: liver } \\
\text { D29: lung and liver }\end{array}$ & $\begin{array}{c}\text { PCR } \\
\text { Southern blot }\end{array}$ & {$[98]$} \\
\hline \multirow{4}{*}{ Chicken } & $4-15$ incubation days & $\begin{array}{l}\text { D4-D7: embryonic pool } \\
\text { D9-D15: liver } \\
\text { D4-D15: yolk sac }\end{array}$ & $\begin{array}{c}\text { EROD } \\
(\text { microsomes }) \\
\left(<1 \mathrm{pmol} / \mathrm{mg} \text { of protein } / \mathrm{min}^{-1}\right) \\
\left(>300<1100 \mathrm{pmol} / \mathrm{mg} \text { of } \mathrm{protein} / \mathrm{min}^{-1}\right) \\
\left(>20<400 \mathrm{pmol} / \mathrm{mg} \text { of protein } / \mathrm{min}^{-1}\right)\end{array}$ & {$[101]$} \\
\hline & 17 incubation days & Liver & $\begin{array}{c}\text { Run-on } \\
\text { transcription assay }\end{array}$ & {$[102]$} \\
\hline & 18 incubation days & $\begin{array}{l}\text { Liver } \\
\text { kidney }\end{array}$ & $\begin{array}{c}\text { EROD } \\
(\mathrm{microsomes}) \\
\left(35 \pm 6 \mathrm{pmol} / \mathrm{mg} \text { of protein } / \mathrm{min}^{-1}\right) \\
\left(25 \pm 9 \mathrm{pmol} / \mathrm{mg} \text { of protein } / \mathrm{min}^{-1}\right)\end{array}$ & {$[103]$} \\
\hline & 10 incubation days & Liver & q-PCR & [104] \\
\hline \multirow{3}{*}{ Zebra Fish } & $\begin{array}{l}8-128 \text { hours after } \\
\text { fertilization (hpf) }\end{array}$ & $\begin{array}{c}8 \text { hpf: germs layers } \\
32-80 \text { hpf: cardiovascular system } \\
\text { 104-128 hpf: cardiovascular } \\
\text { system, liver, intestine, urinary } \\
\text { tract, and kidney }\end{array}$ & $\begin{array}{c}\text { EROD in vivo } \\
\left(>0.08<0.5 \mathrm{pmol} / \mathrm{mg} \text { of protein } / \mathrm{min}^{-1}\right)\end{array}$ & {$[105]$} \\
\hline & $48-120 \mathrm{hpf}$ & Embryonic pool & $\begin{array}{c}\text { q-PCR EROD in vivo } \\
(0.0107-0.0184 \mathrm{pmol} / \mathrm{mg} \text { of } \\
\left.\text { protein } / \mathrm{min}^{-1}\right)\end{array}$ & [106] \\
\hline & $\begin{array}{l}4-8 \text { days after } \\
\text { fertilization }\end{array}$ & Not determined & $\begin{array}{c}\text { EROD in vivo } \\
\left(50-100 \mathrm{fmol} \mathrm{h}^{-1} \text { larva }^{-1}\right)\end{array}$ & {$[107]$} \\
\hline \multirow{2}{*}{ Medaka fish } & $8 \mathrm{hpf}$ & Not determined & $\begin{array}{l}\text { EROD in vivo } \\
\text { (arbitrary units) }\end{array}$ & {$[108]$} \\
\hline & $50-245 \mathrm{hpf}$ & Gallbladder & $\begin{array}{l}\text { EROD in vivo } \\
\text { (arbitrary units) }\end{array}$ & [109] \\
\hline
\end{tabular}


as trachea and lungs, but after induction, it is also detected in other organs such as liver, adrenal gland, bladder, heart, kidney, ovary, placenta, prostate, testis, thyroid, salivary gland, and spleen $[96,151]$. Among these organs, different levels of the protein are detected [152].

\section{Concluding Remarks}

CYP1A1 is a relevant enzyme for biotransformation of environmental compounds into mutagenic metabolites; this fact has a strong effect on worldwide population; therefore, the knowledge of its tridimensional structure as well as its ligands allows us to the rationale search and development of inhibitors that would become chemopreventive agents for diseases related to exposure to CYP1Al activated carcinogens.

On the other hand, the presence of CYP1A1 among several species forces us to choose biological models that share with humans similar CYP1A1 characteristics in order to obtain results able to be extrapolated. The animals frequently used for this purpose are rats and mice, in which some of the regulatory mechanisms and other data, reported here, have been described. Moreover, as already mentioned in the "upregulation of CYP1A1" Section, several pathways could be involved like the recently reported WNT- $\beta$ catenin, RAR, or CAR pathways that regulate CYP1A1 expression by direct interaction with its gene promoter or with that of $A H R$ or both. However, these alternative pathways are poorly described and more studies in this regard are required to know how and what are the factors involved as well as the specific conditions necessary for their action on CYP1A1 expression, like the tissue and its microenvironment or culture cell type used just to mention two of them. The discoveries of pathways that converge in CYP1A1 regulation are opportunities for the selection of new therapeutic targets that allow drug development for chemoprevention.

For the study of CYP1A1, we need to take into account that impairment of gene expression or enzyme activity could lead to adverse effects because it is involved in endogenous metabolism, an issue discussed in "CYP1A1 through development," with particular interest in cardiotoxicity.

The integration of data generated about CYP1A1, factors, and mechanisms that play a role in carcinogen bioactivation will help us to rise up strategies that improve our life quality. In this context, some key questions that need to be addressed are written below.

It will be worth to continue the searching for chemopreventive agents that inhibit CYP1A1 even if it seems to be involved in the normal development of the heart. It is a good strategy to improve chemopreventive agents acting on different regulating CYP1A1 pathways at the same time; meanwhile they have fewer side effects. What is the real contribution of CYP1A1 in the process of carcinogen bioactivation knowing that it shares regulatory elements with additional CYPs of the same family? Do the cardiotoxicity effects produced in the lack of CYP1A1 activity be a window for searching new therapeutic targets for cardiovascular diseases? What is the biological relevance of reactive oxygen species production by CYP1A1? Why do tissues have differences on CYP1A1 expression? Is the tissue-specific, or even cell-specific, expression of
CYP1A1 explained by differences in endogenous metabolism requirements or by alternative modulation of a particular set of AHR co-activators? Do the specific CYP1A1 expression and induction play a role in the development of a particular cancer ligand related?

\section{Competing Interests}

The authors declare that there is no conflict of interests regarding the publication of this paper.

\section{Acknowledgments}

The authors thank Dr. Mariana Flores Torres and Dr. Mauricio Alejandro Olguín Albuerne for critically reviewing the manuscript. The authors Rebeca Santes-Palacios, Diego Ornelas-Ayala, Alexis Hernández-Magaña, Noel Cabañas, Ana Marroquín-Pérez, and Sitlali del Rosario Olguín-Reyes gratefully acknowledge the CONACyT fellowship awarded to each one. This work was supported by grants from DGAPAUNAM IN206212, IN206915, and Fundacion Miguel Aleman.

\section{References}

[1] J. T. M. Buters, J. Doehmer, and F. J. Gonzalez, "Cytochrome P450-null mice," Drug Metabolism Reviews, vol. 31, no. 2, pp. 437-447, 1999.

[2] Y. Shimizu, Y. Nakatsuru, M. Ichinose et al., "Benzo[a]pyrene carcinogenicity is lost in mice lacking the aryl hydrocarbon receptor," Proceedings of the National Academy of Sciences of the United States of America, vol. 97, no. 2, pp. 779-782, 2000.

[3] H. E. Kleiner, S. V. Vulimiri, M. F. Starost, M. J. Reed, and J. DiGiovanni, "Oral administration of the citrus coumarin, isopimpinellin, blocks DNA adduct formation and skin tumor initiation by 7,12-dimethylbenz [a] anthracene in SENCAR mice," Carcinogenesis, vol. 23, no. 10, pp. 1667-1675, 2002.

[4] C. J. MacDonald, H. P. Ciolino, and G. C. Yeh, "Dibenzoylmethane modulates aryl hydrocarbon receptor function and expression of cytochromes P450 1A1, 1A2, and 1B1," Cancer Research, vol. 61, no. 10, pp. 3919-3924, 2001.

[5] M. J. Gunter, R. L. Divi, M. Kulldorff et al., "Leukocyte polycyclic aromatic hydrocarbon-DNA adduct formation and colorectal adenoma," Carcinogenesis, vol. 28, no. 7, pp. 1426-1429, 2007.

[6] D. Li, M. Wang, K. Dhingra, and W. N. Hittelman, "Aromatic DNA adducts in adjacent tissues of breast cancer patients: clues to breast cancer etiology," Cancer Research, vol. 56, no. 2, pp. 287-293, 1996.

[7] D. L. Tang, A. Rundle, D. Warburton et al., "Associations between both genetic and environmental biomarkers and lung cancer: evidence of a greater risk of lung cancer in women smokers," Carcinogenesis, vol. 19, no. 11, pp. 1949-1953, 1998.

[8] R. Bernhardt, "Cytochromes P450 as versatile biocatalysts," Journal of Biotechnology, vol. 124, no. 1, pp. 128-145, 2006.

[9] D. R. Nelson, “The cytochrome P450 homepage," Human Genomics, vol. 4, no. 1, pp. 59-65, 2009.

[10] F. J. Gonzalez, C. L. Crespi, M. Czerwinski, and H. V. Gelboin, "Analysis of human cytochrome P450 catalytic activities and expression," The Tohoku Journal of Experimental Medicine, vol. 168, no. 2, pp. 67-72, 1992. 
[11] S. L. Kelly and D. E. Kelly, "Microbial cytochromes P450: biodiversity and biotechnology. Where do cytochromes P450 come from, what do they do and what can they do for us?" Philosophical transactions of the Royal Society of London. Series B, Biological sciences, vol. 368, no. 1612, 2013.

[12] X. Qi, S. Bakht, B. Qin et al., "A different function for a member of an ancient and highly conserved cytochrome P450 family: from essential sterols to plant defense," Proceedings of the National Academy of Sciences of the United States of America, vol. 103, no. 49, pp. 18848-18853, 2006.

[13] J. H. Thomas, "Rapid birth-death evolution specific to xenobiotic cytochrome P450 genes in vertebrates," PLoS Genetics, vol. 3, no. 5, article e67, 2007.

[14] D. W. Nebert and T. P. Dalton, "The role of cytochrome P450 enzymes in endogenous signalling pathways and environmental carcinogenesis," Nature Reviews Cancer, vol. 6, no. 12, pp. 947960, 2006.

[15] H. M. H. Goldstone and J. J. Stegeman, "A revised evolutionary history of the CYP1A subfamily: gene duplication, gene conversion, and positive selection," Journal of Molecular Evolution, vol. 62, no. 6, pp. 708-717, 2006.

[16] D. W. Nebert, K. Wikvall, and W. L. Miller, "Human cytochromes P450 in health and disease," Philosophical transactions of the Royal Society of London. Series B, Biological sciences, vol. 368, no. 1612, 2013.

[17] J. V. Goldstone, H. M. H. Goldstone, A. M. Morrison et al., "Cytochrome P450 1 genes in early deuterostomes (tunicates and sea urchins) and vertebrates (chicken and frog): origin and diversification of the CYP1 gene family," Molecular Biology and Evolution, vol. 24, no. 12, pp. 2619-2631, 2007.

[18] R. Mitsuo, M. Sato, and T. Itakura, "Cloning, sequencing, and phylogenetic analysis of complementary DNA of novel cytochrome P-450 CYP1A in Japanese eel (Anguilla japonica)," Marine Biotechnology, vol. 3, no. 3, pp. 218-223, 2001.

[19] D. R. Nelson, L. Koymans, T. Kamataki et al., "P450 superfamily: update on new sequences, gene mapping, accession numbers and nomenclature," Pharmacogenetics, vol. 6, no. 1, pp. 1-42, 1996.

[20] Z. Jiang, T. P. Dalton, L. Jin et al., "Toward the evaluation of function in genetic variability: characterizing human SNP frequencies and establishing BAC-transgenic mice carrying the human CYP1A1_CYP1A2 locus," Human Mutation, vol. 25, no. 2, pp. 196-206, 2005.

[21] L. F. Jorge-Nebert, Z. Jiang, R. Chakraborty et al., "Analysis of human CYP1A1 and CYP1A2 genes and their shared bidirectional promoter in eight world populations," Human Mutation, vol. 31, no. 1, pp. 27-40, 2010.

[22] K. W. Bock, "The human Ah receptor: hints from dioxin toxicities to deregulated target genes and physiological functions," Biological Chemistry, vol. 394, no. 6, pp. 729-739, 2013.

[23] T. Ikuta, H. Eguchi, T. Tachibana, Y. Yoneda, and K. Kawajiri, "Nuclear localization and export signals of the human aryl hydrocarbon receptor," The Journal of Biological Chemistry, vol. 273, no. 5, pp. 2895-2904, 1998.

[24] N. Tsuji, K. Fukuda, Y. Nagata et al., "The activation mechanism of the aryl hydrocarbon receptor (AhR) by molecular chaperone HSP90," FEBS Open Bio, vol. 4, pp. 796-803, 2014.

[25] M. Nukaya and C. A. Bradfield, "Conserved genomic structure of the Cyplal and Cypla2 loci and their dioxin responsive elements cluster," Biochemical Pharmacology, vol. 77, no. 4, pp. 654-659, 2009.
[26] J. P. Whitlock Jr., "Induction of cytochrome P4501A1," Annual Review of Pharmacology and Toxicology, vol. 39, pp. 103-125, 1999.

[27] S. T. Okino, D. Pookot, L.-C. Li et al., "Epigenetic inactivation of the dioxin-responsive Cytochrome P4501A1 gene in human prostate cancer," Cancer Research, vol. 66, no. 15, pp. 7420-7428, 2006.

[28] M. Schnekenburger, L. Peng, and A. Puga, "HDAC1 bound to the Cyplal promoter blocks histone acetylation associated with Ah receptor-mediated trans-activation," Biochimica et Biophysica Acta, vol. 1769, no. 9-10, pp. 569-578, 2007.

[29] S. R. Beedanagari, R. T. Taylor, P. Bui, F. Wang, D. W. Nickerson, and O. Hankinson, "Role of epigenetic mechanisms in differential regulation of the dioxin-inducible human CYP1A1 and CYP1B1 genes," Molecular Pharmacology, vol. 78, no. 4, pp. 608-616, 2010.

[30] T. V. Beischlag, J. L. Morales, B. D. Hollingshead, and G. H. Perdew, "The aryl hydrocarbon receptor complex and the control of gene expression," Critical Reviews in Eukaryotic Gene Expression, vol. 18, no. 3, pp. 207-250, 2008.

[31] J. D. Watson, S. D. Prokopec, A. B. Smith, A. B. Okey, R. Pohjanvirta, and P. C. Boutros, "TCDD dysregulation of 13 AHRtarget genes in rat liver," Toxicology and Applied Pharmacology, vol. 274, no. 3, pp. 445-454, 2014.

[32] S. Vaas, L. Kreft, M. Schwarz, and A. Braeuning, "Cooperation of structurally different aryl hydrocarbon receptor agonists and $\beta$-catenin in the regulation of CYP1A expression," Toxicology, vol. 325, pp. e31-e41, 2014.

[33] A. Braeuning, C. Köhle, A. Buchmann, and M. Schwarz, "Coordinate regulation of cytochrome P450 lal expression in mouse liver by the aryl hydrocarbon receptor and the $\beta$-catenin pathway," Toxicological Sciences, vol. 122, no. 1, pp. 16-25, 2011.

[34] P. Schulthess, A. Löffler, S. Vetter et al., "Signal integration by the CYP1A1 promoter-A Quantitative Study," Nucleic Acids Research, vol. 43, no. 11, pp. 5318-5330, 2015.

[35] N.-L. Ge and C. J. Elferink, "A direct interaction between the aryl hydrocarbon receptor and retinoblastoma protein: linking dioxin signaling to the cell cycle," The Journal of Biological Chemistry, vol. 273, no. 35, pp. 22708-22713, 1998.

[36] C. J. Elferink, N.-L. Ge, and A. Levine, "Maximal aryl hydrocarbon receptor activity depends on an interaction with the retinoblastoma protein," Molecular Pharmacology, vol. 59, no. 4, pp. 664-673, 2001.

[37] K. Yoshinari, N. Yoda, T. Toriyabe, and Y. Yamazoe, "Constitutive androstane receptor transcriptionally activates human CYP1A1 and CYP1A2 genes through a common regulatory element in the $5^{\prime}$-flanking region," Biochemical Pharmacology, vol. 79, no. 2, pp. 261-269, 2010.

[38] N. Shibahara, Y. Masunaga, S. Iwano, H. Yamazaki, K. Kiyotani, and T. Kamataki, "Human cytochrome P450 1A1 is a novel target gene of liver X receptor $\alpha$," Drug Metabolism and Pharmacokinetics, vol. 26, no. 5, pp. 451-457, 2011.

[39] K. Araki, K. Watanabe, Y. Yamazoe, and K. Yoshinari, "Liver $\mathrm{X}$ receptor $\alpha$ bidirectionally transactivates human CYP1A1 and CYP1A2 through two cis-elements common to both genes," Toxicology Letters, vol. 215, no. 1, pp. 16-24, 2012.

[40] E. Sérée, P.-H. Villard, J.-M. Pascussi et al., "Evidence for a new human CYP1A1 regulation pathway involving PPAR- $\alpha$ and 2 PPRE sites," Gastroenterology, vol. 127, no. 5, pp. 1436-1445, 2004. 
[41] F. Fallone, P.-H. Villard, L. Decome et al., "PPAR $\alpha$ activation potentiates AhR-induced CYP1A1 expression," Toxicology, vol. 216, no. 2-3, pp. 122-128, 2005.

[42] M. Kutmon, M. P. van Iersel, A. Bohler et al., "PathVisio 3: an extendable pathway analysis toolbox," PLoS Computational Bio$\log y$, vol. 11, no. 2, Article ID e1004085, 2015.

[43] J. Mimura, M. Ema, K. Sogawa, and Y. Fujii-Kuriyama, "Identification of a novel mechanism of regulation of Ah (dioxin) receptor function," Genes and Development, vol. 13, no. 1, pp. 20-25, 1999.

[44] S. I. Karchner, M. J. Jenny, A. M. Tarrant et al., "The active form of human aryl hydrocarbon receptor (AHR) repressor lacks exon 8 , and its Pro ${ }^{185}$ and Ala ${ }^{185}$ variants repress both AHR and hypoxia-inducible factor," Molecular and Cellular Biology, vol. 29, no. 13, pp. 3465-3477, 2009.

[45] C. F. Vogel, W. L. Chang, S. Kado et al., "Transgenic overexpression of Aryl Hydrocarbon Receptor Repressor (AhRR) and AhR-mediated induction of CYP1A1, cytokines," Environmental Health Perspectives, vol. 124, no. 7, pp. 1071-1083, 2016.

[46] C. Weiss, S. K. Kolluri, F. Kiefer, and M. Göttlicher, "Complementation of Ah receptor deficiency in hepatoma cells: negative feedback regulation and cell cycle control by the Ah receptor," Experimental Cell Research, vol. 226, no. 1, pp. 154-163, 1996.

[47] D. P. Jackson, A. D. Joshi, and C. J. Elferink, "Ah receptor pathway intricacies; signaling through diverse protein partners and DNA-motifs," Toxicology Research, vol. 4, no. 5, pp. 11431158, 2015.

[48] N. Zhang and M. K. Walker, "Crosstalk between the aryl hydrocarbon receptor and hypoxia on the constitutive expression of cytochrome P4501A1 mRNA," Cardiovascular Toxicology, vol. 7, no. 4, pp. 282-290, 2007.

[49] J. W. Allen, R. S. Johnson, and S. N. Bhatia, "Hypoxic inhibition of 3-methylcholanthrene-induced CYP1A1 expression is independent of HIF-1alpha," Toxicology Letters, vol. 155, no. 1, pp. 151-159, 2005.

[50] S. U. Vorrink, P. L. Severson, M. V. Kulak, B. W. Futscher, and F. E. Domann, "Hypoxia perturbs aryl hydrocarbon receptor signaling and CYP1A1 expression induced by PCB 126 in human skin and liver-derived cell lines," Toxicology and Applied Pharmacology, vol. 274, no. 3, pp. 408-416, 2014.

[51] F. Vecchini, M. C. Lenoir-Viale, C. Cathelineau, J. Magdalou, B. A. Bernard, and B. Shroot, "Presence of a retinoid responsive element in the promoter region of the human cytochrome P4501A1 gene," Biochemical and Biophysical Research Communications, vol. 201, no. 3, pp. 1205-1212, 1994.

[52] M. Ohno, Y. Ikenaka, and M. Ishizuka, "All-trans retinoic acid inhibits the recruitment of ARNT to DNA, resulting in the decrease of CYP1A1 mRNA expression in HepG2 cells," Biochemical and Biophysical Research Communications, vol. 417, no. 1, pp. 484-489, 2012.

[53] F. Fallone, P.-H. Villard, E. Sérée et al., "Retinoids repress Ah receptor CYP1A1 induction pathway through the SMRT corepressor," Biochemical and Biophysical Research Communications, vol. 322, no. 2, pp. 551-556, 2004.

[54] Y. Morel and R. Barouki, "Down-regulation of cytochrome P450 $1 \mathrm{Al}$ gene promoter by oxidative stress. Critical contribution of nuclear factor 1," The Journal of Biological Chemistry, vol. 273, no. 41, pp. 26969-26976, 1998.

[55] Y. Morel, N. Mermod, and R. Barouki, "An autoregulatory loop controlling CYP1A1 gene expression: role of $\mathrm{H}_{2} \mathrm{O}_{2}$ and NFI," Molecular and Cellular Biology, vol. 19, no. 10, pp. 6825-6832, 1999.
[56] R. Barouki and Y. Morel, "Repression of cytochrome P450 1A1 gene expression by oxidative stress: mechanisms and biological implications," Biochemical Pharmacology, vol. 61, no. 5, pp. 511516, 2001.

[57] K. Monostory, K. Kohalmy, R. A. Prough, L. Kóbori, and L. Vereczkey, "The effect of synthetic glucocorticoid, dexamethasone on CYP1A1 inducibility in adult rat and human hepatocytes," FEBS Letters, vol. 579, no. 1, pp. 229-235, 2005.

[58] R. Vrzal, L. Stejskalova, K. Monostory et al., "Dexamethasone controls aryl hydrocarbon receptor (AhR)-mediated CYP1A1 and CYP1A2 expression and activity in primary cultures of human hepatocytes," Chemico-Biological Interactions, vol. 179, no. 2-3, pp. 288-296, 2009.

[59] W. Zhang, J. M. Shields, K. Sogawa, Y. Fujii-Kuriyama, and V. W. Yang, "The gut-enriched Kruppel-like factor suppresses the activity of the CYPlal promoter in an Spl-dependent fashion," The Journal of Biological Chemistry, vol. 273, no. 28, pp. 1791717925, 1998.

[60] T. E. Paton and K. W. Rentom, "Cytokine-mediated down-regulation of CYP1A1 in Hepal cells," Biochemical Pharmacology, vol. 55, no. 11, pp. 1791-1796, 1998.

[61] H. G. Jeong, J. Y. Kim, C. Y. Choi, H. J. You, and K.-S. Hahm, "Suppression of CYP1A1 expression by 4-nonylphenol in murine Hepa-1clc7 cells," Cancer Letters, vol. 165, no. 1, pp. 95-101, 2001.

[62] N. Gharavi and A. O. S. El-Kadi, "Down-regulation of aryl hydrocarbon receptor-regulated genes by tumor necrosis factor- $\alpha$ and lipopolysaccharide in murine hepatoma Hepa 1clc7 cells," Journal of Pharmaceutical Sciences, vol. 94, no. 3, pp. 493506, 2005.

[63] Z. Abdel-Razzak, P. Loyer, A. Fautrel et al., "Cytokines downregulate expression of major cytochrome P-450 enzymes in adult human hepatocytes in primary culture," Molecular Pharmacology, vol. 44, no. 4, pp. 707-715, 1993.

[64] J. Muntané-Relat, J.-C. Ourlin, J. Domergue, and P. Maurel, "Differential effects of cytokines on the inducible expression of cypla1, CYP1A2, and CYP3A4 in human hepatocytes in primary culture," Hepatology, vol. 22, no. 4, pp. 1143-1153, 1995.

[65] S. Anttila, J. Hakkola, P. Tuominen et al., "Methylation of cytochrome P4501Al promoter in the lung is associated with tobacco smoking," Cancer Research, vol. 63, no. 24, pp. 8623$8628,2003$.

[66] M. Nakajima, M. Iwanari, and T. Yokoi, "Effects of histone deacetylation and DNA methylation on the constitutive and TCDD-inducible expressions of the human CYP1 family in MCF-7 and HeLa cells," Toxicology Letters, vol. 144, no. 2, pp. 247-256, 2003.

[67] S. R. Beedanagari, R. T. Taylor, and O. Hankinson, "Differential regulation of the dioxin-induced Cypla1 and Cyp1b1 genes in mouse hepatoma and fibroblast cell lines," Toxicology Letters, vol. 194, no. 1-2, pp. 26-33, 2010.

[68] J. E. Fraczek, M. Vinken, D. Tourwé, T. Vanhaecke, and V. Rogiers, "Synergetic effects of DNA demethylation and histone deacetylase inhibition in primary rat hepatocytes," Investigational New Drugs, vol. 30, no. 4, pp. 1715-1724, 2012.

[69] X. Tekpli, S. Zienolddiny, V. Skaug, L. Stangeland, A. Haugen, and S. Mollerup, "DNA methylation of the CYP1A1 enhancer is associated with smoking-induced genetic alterations in human lung," International Journal of Cancer, vol. 131, no. 7, pp. 15091516, 2012.

[70] S. U. Vorrink, D. R. Hudachek, and F. E. Domann, "Epigenetic determinants of CYP1A1 induction by the aryl hydrocarbon 
receptor agonist 3,3/,4,4',5-pentachlorobiphenyl (PCB 126)," International Journal of Molecular Sciences, vol. 15, no. 8, pp. 13916-13931, 2014.

[71] H.-J. Park, Y.-J. Choi, J. W. Kim et al., "Differences in the epigenetic regulation of cytochrome $\mathrm{P} 450$ genes between human embryonic stem cell-derived hepatocytes and primary hepatocytes," PLoS ONE, vol. 10, no. 7, Article ID e0132992, 2015.

[72] L. Xu, T. S. Ruh, and M. F. Ruh, "Effect of the histone deacetylase inhibitor trichostatin A on the responsiveness of rat hepatocytes to dioxin," Biochemical Pharmacology, vol. 53, no. 7, pp. 951-957, 1997.

[73] L. A. Hooven, B. Mahadevan, C. Keshava et al., "Effects of suberoylanilide hydroxamic acid and trichostatin A on induction of cytochrome P450 enzymes and benzo[a]pyrene DNA adduct formation in human cells," Bioorganic and Medicinal Chemistry Letters, vol. 15, no. 5, pp. 1283-1287, 2005.

[74] T. Henkens, P. Papeleu, G. Elaut, M. Vinken, V. Rogiers, and T. Vanhaecke, "Trichostatin A, a critical factor in maintaining the functional differentiation of primary cultured rat hepatocytes," Toxicology and Applied Pharmacology, vol. 218, no. 1, pp. 64-71, 2007.

[75] S. H. Lee, H. J. Yu, S. Lee, and D.-Y. Ryu, "Characterization of the Gly45Asp variant of human cytochrome P450 1A1 using recombinant expression," Toxicology Letters, vol. 239, no. 2, pp. 81-89, 2015.

[76] S. H. Lee, S. Kang, M. S. Dong et al., "Characterization of the Ala62Pro polymorphic variant of human cytochrome P450 1A1 using recombinant protein expression," Toxicology and Applied Pharmacology, vol. 285, no. 3, pp. 159-169, 2015.

[77] B. C. Lewis, P. I. Mackenzie, and J. O. Miners, "Application of homology modeling to generate CYP1A1 mutants with enhanced activation of the cancer chemotherapeutic prodrug dacarbazine," Molecular Pharmacology, vol. 80, no. 5, pp. 879888, 2011.

[78] J. Liu, S. S. Ericksen, M. Sivaneri, D. Besspiata, C. W. Fisher, and G. D. Szklarz, "The effect of reciprocal active site mutations in human cytochromes P450 1A1 and 1A2 on alkoxyresorufin metabolism," Archives of Biochemistry and Biophysics, vol. 424, no. 1, pp. 33-43, 2004.

[79] B. C. Lewis, P. I. Mackenzie, and J. O. Miners, "Comparative homology modeling of human cytochrome P4501A1 (CYP1A1) and confirmation of residues involved in 7-ethoxyresorufin $\mathrm{O}$ deethylation by site-directed mutagenesis and enzyme kinetic analysis," Archives of Biochemistry and Biophysics, vol. 468, no. 1, pp. 58-69, 2007.

[80] T. Shimada, C. L. Hayes, H. Yamazaki et al., "Activation of chemically diverse procarcinogens by human cytochrome P450 1B1," Cancer Research, vol. 56, no. 13, pp. 2979-2984, 1996.

[81] T. Shimada, Y. Oda, E. M. J. Gillam, F. P. Guengerich, and K. Inoue, "Metabolic activation of polycyclic aromatic hydrocarbons and other procarcinogens by cytochromes P450 1A1 and P450 1B1 allelic variants and other human cytochromes P450 in Salmonella Typhimurium NM2009," Drug Metabolism and Disposition, vol. 29, no. 9, pp. 1176-1182, 2001.

[82] M. Miyazaki, E. Sugawara, T. Yoshimura, H. Yamazaki, and T. Kamataki, "Mutagenic activation of betel quid-specific N-nitrosamines catalyzed by human cytochrome P450 coexpressed with NADPH-cytochrome P450 reductase in Salmonella typhimurium YG7108," Mutation Research, vol. 581, no. 1-2, pp. 165171, 2005.

[83] C. A. F. Aiub, J. L. Mazzei, L. F. R. Pinto, and I. Felzenszwalb, "Evaluation of nitroreductase and acetyltransferase participation in N-nitrosodiethylamine genotoxicity," ChemicoBiological Interactions, vol. 161, no. 2, pp. 146-154, 2006.

[84] M. J. Seaton, P. M. Schlosser, J. A. Bond, and M. A. Medinsky, "Benzene metabolism by human liver microsomes in relation to cytochrome P450 2E1 activity," Carcinogenesis, vol. 15, no. 9, pp. 1799-1806, 1994.

[85] S. Marumoto, Y. Oda, and M. Miyazawa, "Antigenotoxic activity of naturally occurring furanocoumarins," Environmental and Molecular Mutagenesis, vol. 52, no. 8, pp. 646-657, 2011.

[86] T. Shimada, M. V. Martin, D. Pruess-Schwartz, L. J. Marnett, and F. P. Guengerich, "Roles of individual human cytochrome P-450 enzymes in the bioactivation of benzo(a)pyrene, 7,8-dihydroxy7,8-dihydrobenzo(a)pyrene, and other dihydrodiol derivatives of polycyclic aromatic hydrocarbons," Cancer Research, vol. 49, no. 22, pp. 6304-6312, 1989.

[87] M. Stiborová, M. Hájek, E. Frei, and H. H. Schmeiser, “Carcinogenic and nephrotoxic alkaloids aristolochic acids upon activation by NADPH: cytochrome $\mathrm{P} 450$ reductase form adducts found in DNA of patients with Chinese herbs nephropathy," General Physiology and Biophysics, vol. 20, no. 4, pp. 375-392, 2001.

[88] I. Duarte Silva, A. S. Rodrigues, J. Gaspar, R. Maia, A. Laires, and J. Rueff, "Involvement of rat cytochrome $1 \mathrm{Al}$ in the biotransformation of kaempferol to quercetin: relevance to the genotoxicity of kaempferol," Mutagenesis, vol. 12, no. 5, pp. 383-390, 1997.

[89] I. Duarte Silva, A. S. Rodrigues, J. Gaspar, A. Laires, and J. Rueff, "Metabolism of galangin by rat cytochromes P450: relevance to the genotoxicity of galangin," Mutation Research-Genetic Toxicology and Environmental Mutagenesis, vol. 393, no. 3, pp. 247-257, 1997.

[90] D. Aimová, L. Svobodová, V. Kotrbová et al., “The anticancer drug ellipticine is a potent inducer of rat cytochromes P450 $1 \mathrm{~A} 1$ and 1A2, thereby modulating its own metabolism," Drug Metabolism and Disposition, vol. 35, no. 10, pp. 1926-1934, 2007.

[91] M. Backlund, I. Johansson, S. Mkrtchian, and M. IngelmanSundberg, "Signal transduction-mediated activation of the aryl hydrocarbon receptor in rat hepatoma H4IIE cells," The Journal of Biological Chemistry, vol. 272, no. 50, pp. 31755-31763, 1997.

[92] I. J. Cho and S. G. Kim, "Oltipraz inhibits 3-methylcholanthrene induction of CYP1A1 by CCAAT/enhancer-binding protein activation," The Journal of Biological Chemistry, vol. 278, no. 45, pp. 44103-44112, 2003.

[93] D. Schwarz, P. Kisselev, S. S. Ericksen et al., "Arachidonic and eicosapentaenoic acid metabolism by human CYP1A1: highly stereoselective formation of 17(R),18(S)-epoxyeicosatetraenoic acid," Biochemical Pharmacology, vol. 67, no. 8, pp. 1445-1457, 2004.

[94] X. Ma, J. R. Idle, K. W. Krausz, and F. J. Gonzalez, "Metabolism of melatonin by human cytochromes P450," Drug Metabolism and Disposition, vol. 33, no. 4, pp. 489-494, 2005.

[95] A. J. Lee, M. X. Cai, P. E. Thomas, A. H. Conney, and B. T. Zhu, "Characterization of the oxidative metabolites of $17 \beta$ estradiol and estrone formed by 15 selectively expressed human cytochrome p450 isoforms," Endocrinology, vol. 144, no. 8, pp. 3382-3398, 2003.

[96] D. Choudhary, I. Jansson, I. Stoilov, M. Sarfarazi, and J. B. Schenkman, "Expression patterns of mouse and human CYP orthologs (families 1-4) during development and in different adult tissues," Archives of Biochemistry and Biophysics, vol. 436, no. 1, pp. 50-61, 2005.

[97] H.-Y. L. Yang, Q. P. Lee, A. E. Rettie, and M. R. Juchau, "Functional cytochrome P4503A isoforms in human embryonic 
tissues: expression during organogenesis," Molecular Pharmacology, vol. 46, no. 5, pp. 922-928, 1994.

[98] C. J. Omiecinski, C. A. Redlich, and P. Costa, "Induction and developmental expression of cytochrome P450IA1 messenger RNA in rat and human tissues: detection by the polymerase chain reaction," Cancer Research, vol. 50, no. 14, pp. 4315-4321, 1990.

[99] D. Choudhary, I. Jansson, J. B. Schenkman, M. Sarfarazi, and I. Stoilov, "Comparative expression profiling of 40 mouse cytochrome P450 genes in embryonic and adult tissues," Archives of Biochemistry and Biophysics, vol. 414, no. 1, pp. 91-100, 2003.

[100] S. J. Campbell, C. J. Henderson, D. C. Anthony, D. Davidson, A. J. Clark, and C. R. Wolf, "The murine Cyplal gene is expressed in a restricted spatial and temporal pattern during embryonic development," The Journal of Biological Chemistry, vol. 280, no. 7, pp. 5828-5835, 2005.

[101] B. Heinrich-Hirsch, D. Hofmann, J. Webb, and D. Neubert, "Activity of aldrinepoxidase, 7-ethoxycoumarin-O-deethylase and 7-ethoxyresorufin-O-deethylase during the development of chick embryos in ovo," Archives of Toxicology, vol. 64, no. 2, pp. 128-134, 1990.

[102] S. S. Mahajan and A. B. Rifkind, "Transcriptional activation of avian CYP1A4 and CYP1A5 by 2,3,7,8-tetrachlorodibenzo-pdioxin: differences in gene expression and regulation compared to mammalian CYP1A1 and CYP1A2," Toxicology and Applied Pharmacology, vol. 155, no. 1, pp. 96-106, 1999.

[103] M. Gannon, D. Gilday, and A. B. Rifkind, "TCDD induces CYP1A4 and CYP1A5 in chick liver and kidney and only CYP1A4, an enzyme lacking arachidonic acid epoxygenase activity, in myocardium and vascular endothelium," Toxicology and Applied Pharmacology, vol. 164, no. 1, pp. 24-37, 2000.

[104] N. Fujisawa, S. M. M. Nakayama, Y. Ikenaka, and M. Ishizuka, "TCDD-induced chick cardiotoxicity is abolished by a selective cyclooxygenase-2 (COX-2) inhibitor NS398," Archives of Toxicology, vol. 88, no. 9, pp. 1739-1748, 2014.

[105] J. C. Otte, A. D. Schmidt, H. Hollert, and T. Braunbeck, "Spatiotemporal development of CYP1 activity in early life-stages of zebrafish (Danio rerio)," Aquatic Toxicology, vol. 100, no. 1, pp. 38-50, 2010.

[106] J. Bräunig, S. Schiwy, O. Broedel et al., "Time-dependent expression and activity of cytochrome P450 1s in early lifestages of the zebrafish (Danio rerio)," Environmental Science and Pollution Research, vol. 22, no. 21, pp. 16319-16328, 2015.

[107] P. Noury, O. Geffard, R. Tutundjian, and J. Garric, "Non destructive in vivo measurement of ethoxyresorufin biotransformation by zebrafish prolarva: development and application," Environmental Toxicology, vol. 21, no. 4, pp. 324-331, 2006.

[108] J.-L. Mu, X.-H. Wang, F. Jin, J.-Y. Wang, and H.-S. Hong, "The role of cytochrome P4501A activity inhibition in three- to five-ringed polycyclic aromatic hydrocarbons embryotoxicity of marine medaka (Oryzias melastigma)," Marine Pollution Bulletin, vol. 64, no. 7, pp. 1445-1451, 2012.

[109] M. González-Doncel, G. Carbonell, L. San Segundo, S. Sastre, E. M. Beltrán, and C. Fernández-Torija, "Stage-dependent ethoxyresorufin-O-deethylase (EROD) in vivo activity in medaka (Oryzias latipes) embryos," Chemosphere, vol. 135, pp. 108-115, 2015.

[110] A. Ramamoorthy and T. C. Skaar, "In silico identification of microRNAs predicted to regulate the drug metabolizing cytochrome P450 genes," Drug Metabolism Letters, vol. 5, no. 2, pp. 126-131, 2011.
[111] Y. M. Choi, S. An, E.-M. Lee et al., "CYP1A1 is a target of miR892a-mediated post-transcriptional repression," International Journal of Oncology, vol. 41, no. 1, pp. 331-336, 2012.

[112] J. K. Rieger, K. Klein, S. Winter, and U. M. Zanger, "Expression variability of absorption, distribution, metabolism, excretionrelated microRNAs in human liver: influence of nongenetic factors and association with gene expression," Drug Metabolism and Disposition, vol. 41, no. 10, pp. 1752-1762, 2013.

[113] K. S. Burgess, S. Philips, E. A. Benson et al., "Age-related changes in MicroRNA expression and pharmacogenes in human liver," Clinical Pharmacology and Therapeutics, vol. 98, no. 2, pp. 205215, 2015

[114] N. P. Singh, U. P. Singh, H. Guan, P. Nagarkatti, and M. Nagarkatti, "Prenatal exposure to TCDD triggers significant modulation of microRNA expression profile in the thymus that affects consequent gene expression," PLoS ONE, vol. 7, no. 9, Article ID e45054, 2012.

[115] D. Simic, C. Euler, E. Haines et al., "MicroRNA changes associated with atypical CYP1A1 inducer BMS-764459," Toxicology, vol. 311, no. 3, pp. 169-177, 2013.

[116] V. Werlinder, M. Backlund, A. Zhukov, and M. IngelmanSundberg, "Transcriptional and post-translational regulation of CYP1A1 by primaquine," Journal of Pharmacology and Experimental Therapeutics, vol. 297, no. 1, pp. 206-214, 2001.

[117] H. M. Korashy and A. O. S. El-Kadi, "Regulatory mechanisms modulating the expression of cytochrome P450 1Al gene by heavy metals," Toxicological Sciences, vol. 88, no. 1, pp. 39-51, 2005.

[118] M. A. M. El Gendy, A. A. Soshilov, M. S. Denison, and A. O. S. El-Kadi, "Transcriptional and posttranslational inhibition of dioxin-mediated induction of CYP1A1 by harmine and harmol," Toxicology Letters, vol. 208, no. 1, pp. 51-61, 2012.

[119] R. H. Elbekai and A. O. S. El-Kadi, "Modulation of aryl hydrocarbon receptor-regulated gene expression by arsenite, cadmium, and chromium," Toxicology, vol. 202, no. 3, pp. 249-269, 2004.

[120] I. E. A. Amara, A. Anwar-Mohamed, and A. O. S. El-Kadi, "Posttranslational mechanisms modulating the expression of the cytochrome P450 1A1 gene by methylmercury in HepG2 cells: a role of heme oxygenase-1," Toxicology Letters, vol. 219, no. 3, pp. 239-247, 2013.

[121] D. A. Gideon, R. Kumari, A. M. Lynn, and K. M. Manoj, "What is the functional role of $\mathrm{N}$-terminal transmembrane helices in the metabolism mediated by liver microsomal cytochrome P450 and its reductase?" Cell Biochemistry and Biophysics, vol. 63, no. 1, pp. 35-45, 2012.

[122] D. Werck-Reichhart and R. Feyereisen, "Cytochromes P450: a success story," Genome Biology, vol. 1, no. 6, Article ID REVIEWS3003, 2000.

[123] J. W. Park, J. R. Reed, L. M. Brignac-Huber, and W. L. Backes, "Cytochrome $\mathrm{P} 450$ system proteins reside in different regions of the endoplasmic reticulum," Biochemical Journal, vol. 464, no. 2, pp. 241-249, 2014.

[124] J. W. Park, J. R. Reed, and W. L. Backes, "The localization of cytochrome P450s CYP1A1 and CYP1A2 into different lipid microdomains is governed by their N-terminal and internal protein regions," Journal of Biological Chemistry, vol. 290, no. 49, pp. 29449-29460, 2015.

[125] A. A. Walsh, G. D. Szklarz, and E. E. Scott, "Human cytochrome P450 1A1 structure and utility in understanding drug and xenobiotic metabolism," The Journal of Biological Chemistry, vol. 288, no. 18, pp. 12932-12943, 2013. 
[126] S. S. Kesharwani, P. P. Nandekar, P. Pragyan, V. Rathod, and A. T. Sangamwar, "Characterization of differences in substrate specificity among CYP1A1, CYP1A2 and CYP1B1: an integrated approach employing molecular docking and molecular dynamics simulations," Journal of Molecular Recognition, vol. 29, no. 8, pp. 370-390, 2016.

[127] W. Honma, W. Li, H. Liu, E. E. Scott, and J. R. Halpert, "Functional role of residues in the helix $\mathrm{B}^{\prime}$ region of cytochrome $\mathrm{P} 450$ 2B1," Archives of Biochemistry and Biophysics, vol. 435, no. 1, pp. 157-165, 2005.

[128] N. Mast, M. A. White, I. Bjorkhem, E. F. Johnson, C. D. Stout, and I. A. Pikuleva, "Crystal structures of substrate-bound and substrate-free cytochrome P450 46A1, the principal cholesterol hydroxylase in the brain," Proceedings of the National Academy of Sciences of the United States of America, vol. 105, no. 28, pp. 9546-9551, 2008.

[129] Y. Zhao, L. Sun, B. K. Muralidhara et al., "Structural and thermodynamic consequences of 1-(4-chlorophenyl)imidazole binding to cytochrome P450 2B4," Biochemistry, vol. 46, no. 41, pp. 11559-11567, 2007.

[130] M. B. Shah, P. R. Wilderman, J. Pascual, Q. Zhang, C. D. Stout, and J. R. Halpert, "Conformational adaptation of human cytochrome P450 2B6 and rabbit cytochrome P450 2B4 revealed upon binding multiple amlodipine molecules," Biochemistry, vol. 51, no. 37, pp. 7225-7238, 2012.

[131] J. Liu, J. Sridhar, and M. Foroozesh, "Cytochrome P450 family 1 inhibitors and structure-activity relationships," Molecules, vol. 18, no. 12, pp. 14470-14495, 2013.

[132] Q. Ma and A. Y. H. Lu, "CYP1A induction and human risk assessment: an evolving tale of in vitro and in vivo studies," Drug Metabolism and Disposition, vol. 35, no. 7, pp. 1009-1016, 2007.

[133] M. A. Butler, F. P. Guengerich, and F. F. Kadlubar, "Metabolic oxidation of the carcinogens 4-aminobiphenyl and 4,4'methylene-bis(2-chloroaniline) by human hepatic microsomes and by purified rat hepatic cytochrome P-450 monooxygenases," Cancer research, vol. 49, no. 1, pp. 25-31, 1989.

[134] A. Anwar-Mohamed, R. H. Elbekai, and A. O. S. El-Kadi, "Regulation of CYP1A1 by heavy metals and consequences for drug metabolism," Expert Opinion on Drug Metabolism \& Toxicology, vol. 5, no. 5, pp. 501-521, 2009.

[135] J. Cui and S. Li, "Inhibitors and prodrugs targeting CYP1: a novel approach in cancer prevention and therapy," Current Medicinal Chemistry, vol. 21, no. 5, pp. 519-552, 2014.

[136] S. Rendic and F. P. Guengerich, "Summary of information on the effects of ionizing and non-ionizing radiation on cytochrome P450 and other drug metabolizing enzymes and transporters," Current Drug Metabolism, vol. 13, no. 6, pp. 787-814, 2012.

[137] E. Carosati, "Modelling cytochromes P450 binding modes to predict P450 inhibition, metabolic stability and isoform selectivity," Drug Discovery Today: Technologies, vol. 10, no. 1, pp. e167-e175, 2013.

[138] J. G. Zou, Y. T. Ma, X. Xie et al., "The association between CYP1A1 genetic polymorphisms and coronary artery disease in the Uygur and Han of China," Lipids in Health and Disease, vol. 13, article 145, 2014.

[139] V. Lança, P. Alcântara, J. Braz-Nogueira, and M. P. Bicho, "Cytochrome P450 1A1 (CYP1A1) T6325C polymorphism might modulate essential hypertension-associated stroke risk," Revista Portuguesa de Cardiologia, vol. 23, no. 3, pp. 343-355, 2004.

[140] M. D. Jarvis, B. R. Palmer, A. P. Pilbrow et al., "CYP1A1 MSPI (T6235C) gene polymorphism is associated with mortality in acute coronary syndrome patients," Clinical and Experimental Pharmacology \& Physiology, vol. 37, no. 2, pp. 193-198, 2010.

[141] D. M. Wassenberg and R. T. Di Giulio, "Synergistic embryotoxicity of polycyclic aromatic hydrocarbon aryl hydrocarbon receptor agonists with cytochrome P4501A inhibitors in Fundulus heteroclitus," Environmental Health Perspectives, vol. 112, no. 17, pp. 1658-1664, 2004.

[142] G. Bozinovic, T. L. Sit, R. Di Giulio, L. F. Wills, and M. F. Oleksiak, "Genomic and physiological responses to strong selective pressure during late organogenesis: few gene expression changes found despite striking morphological differences," BMC Genomics, vol. 14, no. 1, article no. 779, 2013.

[143] J. Yin, J.-M. Yang, F. Zhang, P. Miao, Y. Lin, and M.-L. Chen, "Individual and joint toxic effects of cadmium sulfate and $\alpha$-naphthoflavone on the development of zebrafish embryo," Journal of Zhejiang University: Science B, vol. 15, no. 9, pp. 766775, 2014.

[144] M. K. Walker, R. S. Pollenz, and S. M. Smith, "Expression of the aryl hydrocarbon receptor (AhR) and AhR nuclear translocator during chick cardiogenesis is consistent with 2,3,7,8tetrachlorodibenzo-p-dioxin-induced heart defects," Toxicology and Applied Pharmacology, vol. 143, no. 2, pp. 407-419, 1997.

[145] C. W. Matson, A. R. Timme-Laragy, and R. T. Di Giulio, "Fluoranthene, but not benzo[a]pyrene, interacts with hypoxia resulting in pericardial effusion and lordosis in developing zebrafish," Chemosphere, vol. 74, no. 1, pp. 149-154, 2008.

[146] S. A. Carney, R. E. Peterson, and W. Heideman, "2,3,7,8-Tetrachlorodibenzo-p-dioxin activation of the aryl hydrocarbon receptor/aryl hydrocarbon receptor nuclear translocator pathway causes developmental toxicity through a CYP1A-independent mechanism in zebrafish," Molecular Pharmacology, vol. 66 , no. 3, pp. 512-521, 2004.

[147] J. P. Incardona, T. K. Collier, and N. L. Scholz, "Defects in cardiac function precede morphological abnormalities in fish embryos exposed to polycyclic aromatic hydrocarbons," Toxicology and Applied Pharmacology, vol. 196, no. 2, pp. 191-205, 2004.

[148] C. W. Matson, B. W. Clark, M. J. Jenny, C. R. Fleming, M. E. Hahn, and R. T. Di Giulio, "Development of the morpholino gene knockdown technique in Fundulus heteroclitus: a tool for studying molecular mechanisms in an established environmental model," Aquatic Toxicology, vol. 87, no. 4, pp. 289-295, 2008.

[149] T. P. Dalton, M. Z. Dieter, R. S. Matlib et al., "Targeted knockout of Cyplal gene does not alter hepatic constitutive expression of other genes in the mouse [Ah] battery," Biochemical and Biophysical Research Communications, vol. 267, no. 1, pp. 184-189, 2000.

[150] L. N. Agbor, M. T. Walsh, J. R. Boberg, and M. K. Walker, "Elevated blood pressure in cytochrome P4501A1 knockout mice is associated with reduced vasodilation to omega-3 polyunsaturated fatty acids," Toxicology and Applied Pharmacology, vol. 264, no. 3, pp. 351-360, 2012.

[151] I. Bièche, C. Narjoz, T. Asselah et al., "Reverse transcriptasePCR quantification of mRNA levels from cytochrome (CYP)1, CYP2 and CYP3 families in 22 different human tissues," Pharmacogenetics and Genomics, vol. 17, no. 9, pp. 731-742, 2007.

[152] M. Uhlén, L. Fagerberg, B. M. Hallström et al., “Tissue-based map of the human proteome," Science, vol. 347, no. 6220, Article ID 1260419, 2015. 

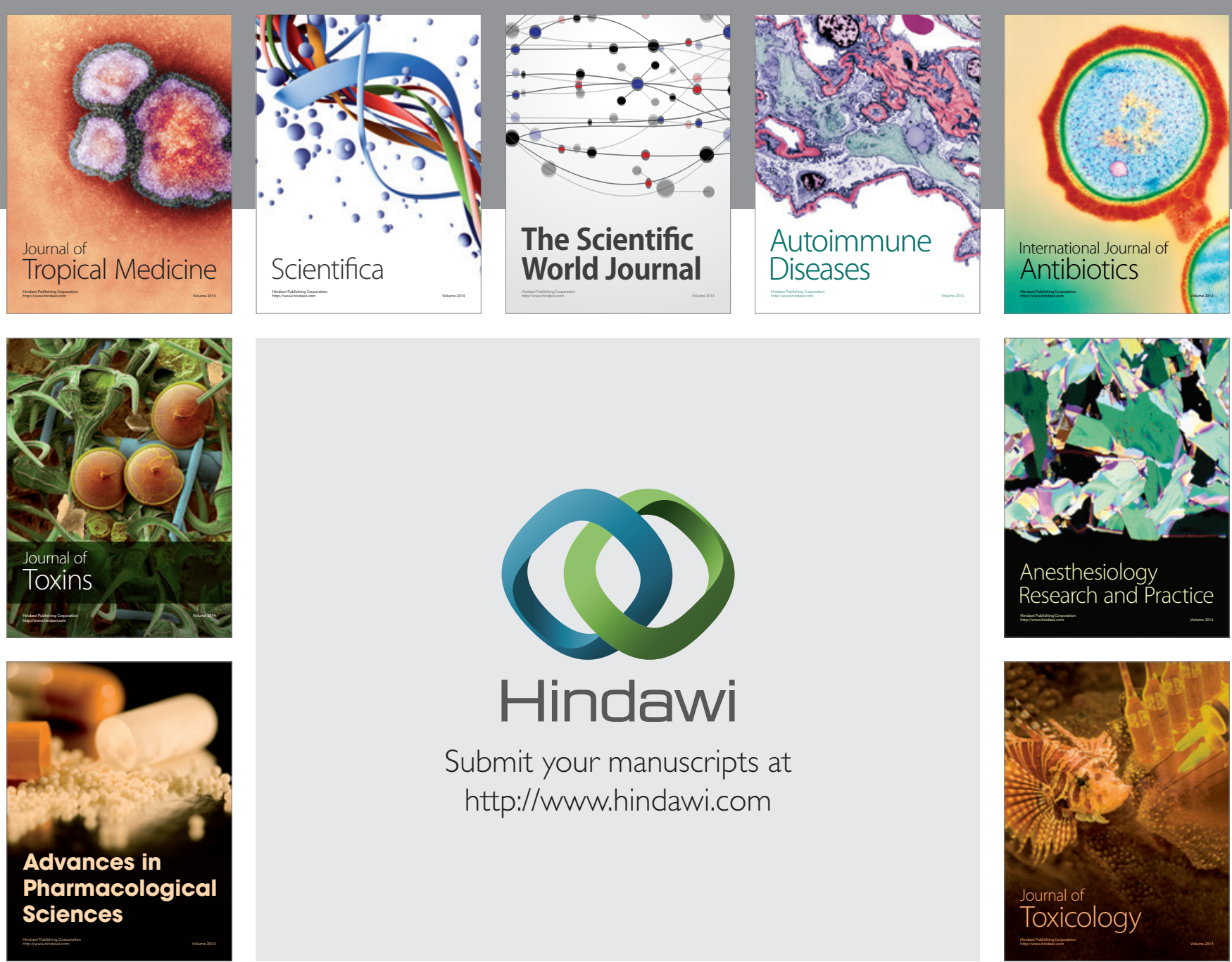

\section{Hindawi}

Submit your manuscripts at

http://www.hindawi.com
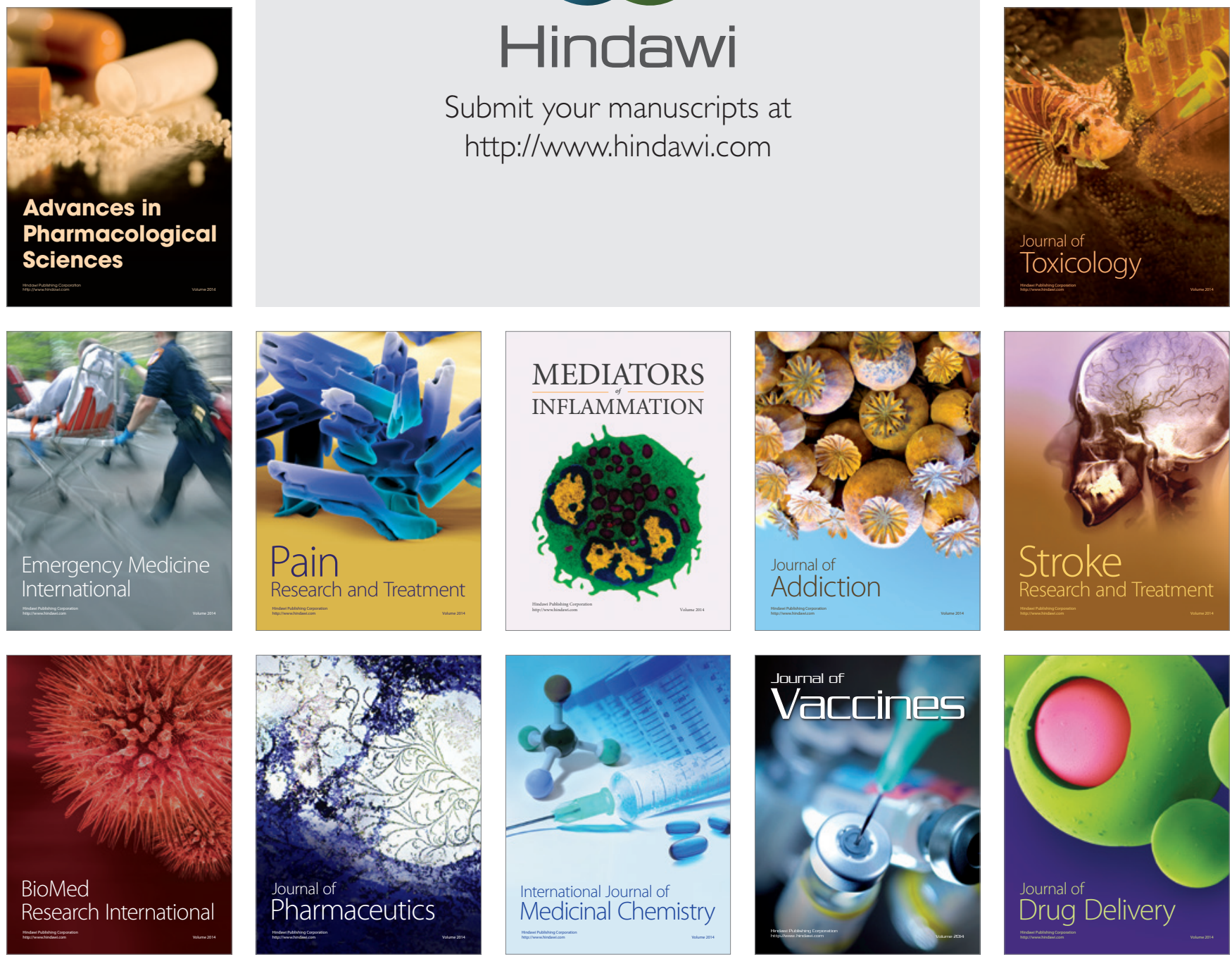